NBER WORKING PAPER SERIES

\title{
DO CONDITIONAL CASH TRANSFERS IMPROVE ECONOMIC OUTCOMES IN THE NEXT GENERATION? EVIDENCE FROM MEXICO
}

\author{
Susan W. Parker \\ Tom Vogl \\ Working Paper 24303 \\ http://www.nber.org/papers/w24303 \\ NATIONAL BUREAU OF ECONOMIC RESEARCH \\ 1050 Massachusetts Avenue \\ Cambridge, MA 02138 \\ February 2018, Revised January 2021
}

We are grateful to seminar participants at the BREAD/CEPR/STICERD/TCD Conference on Development Economics, CIDE, El Colegio de Mexico, the Florida Economics Seminar, Georgetown, George Mason, Monash, NEUDC, PAA, Princeton, UC San Diego, Universidad Iberoamericana, University of Hawaii, and University of Maryland for helpful comments. The views expressed herein are those of the authors and do not necessarily reflect the views of the National Bureau of Economic Research.

NBER working papers are circulated for discussion and comment purposes. They have not been peer-reviewed or been subject to the review by the NBER Board of Directors that accompanies official NBER publications.

(C) 2018 by Susan W. Parker and Tom Vogl. All rights reserved. Short sections of text, not to exceed two paragraphs, may be quoted without explicit permission provided that full credit, including (๑) notice, is given to the source. 
Do Conditional Cash Transfers Improve Economic Outcomes in the Next Generation? Evidence from Mexico

Susan W. Parker and Tom Vogl

NBER Working Paper No. 24303

February 2018, Revised January 2021

JEL No. I25,I38,J24,O15

\begin{abstract}
Conditional cash transfer programs have spread to over 60 countries in the past two decades, but little is known about their long-term effects. We estimate the lasting impact of childhood exposure to Mexico's flagship program Progresa by leveraging the age structure of benefits and geographic variation in early program penetration nationwide. Childhood exposure improves women's outcomes in early adulthood, with increases in educational attainment, geographic mobility, labor market performance, and household living standards. For men, effects are smaller and more difficult to distinguish from spatial convergence.
\end{abstract}

Susan W. Parker

4109 Van Munching Hall

University of Maryland

College Park, MD 20742

swparker@umd.edu

Tom Vogl

Department of Economics

University of California at San Diego

9500 Gilman Drive

La Jolla, CA 92093

and NBER

tvogl@ucsd.edu 


\section{Introduction}

Conditional cash transfer (CCT) programs were first introduced two decades ago and have since spread around the world, now operating in more than 60 countries, in many cases representing a key government strategy for reducing poverty. By linking monetary transfers to children's human capital investment, the programs aim to both alleviate current poverty and reduce future poverty by increasing the human capital levels of children and thus their lifetime earnings potential. One of the earliest of these programs was Mexico's Progresa, which began in 1997 and is well known due to its initial randomized evaluation, the basis for numerous published studies (Parker and Todd, 2017). ${ }^{1}$ The program's novelty and positive evaluation findings contributed to both a large scaleup within Mexico and the spread of its key features to new programs around the world. CCT programs now operate throughout Latin America, in a number of poor countries in Africa and Asia, and even in a few developed countries, including the United States. Using data on the long-term outcomes of Progresa's earliest beneficiaries, this paper investigates whether this landmark program achieved the second of the dual goals: to improve economic wellbeing in the next generation.

Several studies of Progresa and other CCT programs have shown positive program impacts on the education levels of poor youth (Fizbein and Schady, 2009; Baird et al., 2013; Parker and Todd, 2017). Nevertheless, evidence on whether these increases in education translate to better economic outcomes in the next generation is limited. Because these programs explicitly seek to improve the economic outcomes of exposed youth when they grow up, information on long-run outcomes is crucial for assessing their benefits. In part, the lack of evidence reflects the necessity of a long follow-up for measuring impacts on economic outcomes for youth beneficiaries, and long follow-ups of experimental evaluations are costly and organizationally difficult, especially in contexts with high rates of migration. Furthermore, the childhood beneficiaries of these programs are only now just reaching adulthood. A recent literature has begun to follow up the original study cohorts from experimental evaluations of CCTs, although often with limited sampling frames, small samples, or short followup periods. We build on these efforts by leveraging Progresa's nationwide rollout, comparing early beneficiaries to a slightly older group that was too old to benefit much from education transfers,

\footnotetext{
${ }^{1}$ The program began in 1997 as Progresa (Programa de Educación, Salúd y Alimentación), was renamed Oportunidades in 2001 at the start of the Fox presidency, and was renamed Prospera in 2013 during the Peña Nieto presidency. It ceased operation in 2019 during the presidency of López Obrador, who replaced it with the education grant program Becas Benito Juarez, which conditions on enrollment but not attendance.
} 
across municipalities with varying early program penetration. This approach allows us to consider a more sustained intervention than most experimental evaluations of CCT programs and also to evaluate a nationwide program at scale, improving external validity and relevance to policymakers (Muralidharan and Niehaus, 2017).

The experimental follow-ups, mostly of CCT pilot programs, find modest effects on schooling and work. ${ }^{2}$ Barham, Macours, and Maluccio $(2017,2018)$ study a CCT experiment in 42 Nicaraguan communities, in which households were randomized to early (2000-2003) or late (2003-2005) receipt of transfers. At ten-year follow-up, men aged 9 to 12 at baseline showed positive effects of early receipt on educational attainment, test scores, off-farm work, labor migration, and income. Women in the same cohort showed positive effects on non-educational outcomes but weak to null effects on attainment and test scores. The crossover design—with transfers ending for early communities as they started for late communities-complicates interpretation because transfers flowed only to the control group during the late period. A Honduran pilot program avoids this complication because the program never expanded to control areas. Ham and Michelson (2018) follow up the 70 study municipalities eight years after they were randomized to demand-side transfers (a conventional CCT), transfers combined with supply-side subsidies, or control, finding positive effects only of the combined intervention on education for both sexes and on female work. However, Molina Millán et al. (2020) revisit the program at thirteen-year follow-up and find positive effects of the conventional CCT on education for both sexes, international migration for men, and mostly insignificant labor market effects for both sexes. ${ }^{3}$

For Progresa specifically, efforts to analyze longer-run outcomes of children in the experimental cohort have been hampered by extremely high rates of attrition, with at least 25 percent of the cohort attriting within 10 years and over 99 percent lost within our follow-up period (RodríguezOreggia and Freije, 2012; Kugler and Rojas, 2018). ${ }^{4}$ Even fewer studies focus on household-level wellbeing in the longer run. The closest in this area is Gertler, Martinez and Rubio-Codina's (2012) six-year follow-up of households in the experimental cohort, which finds that longer exposure to

\footnotetext{
${ }^{2}$ A separate literature studies whether early exposure to CCTs as infants leads to better school outcomes when children begin school (Behrman, Parker and Todd, 2009; Sanchez Chico, Macours, Maluccio, and Stampini, 2020).

${ }^{3}$ Other CCT studies showing positive longer term effects on education attainment include Barrera-Osorio, Linden and Saavedra (2017) on Colombia and Cahyadi et al. (2020) on Indonesia. With a shorter horizon, Baird, McIntosh and Ozler (2019) estimate the effects of a 2-year CCT program on adolescent females in Malawi 2-4 years after the program ended. While the CCT increased schooling in certain sub-samples, labor market outcomes were unaffected.

${ }^{4}$ These longer-run studies using Progresa's original evaluation sample find both positive and null results, highlighting how high and selective attrition rates make results sensitive to methodological choices.
} 
the program raises household consumption levels.

We estimate the long-term impacts of Progresa in a quasi-experimental design using census data linked to administrative data on program enrollment. We study the educational, labor market, household, and demographic outcomes of the program's earliest beneficiaries, who were of primary school age when the program began in 1997 and are now young adults. Following up this group in the early stages of adulthood, we rely on a difference-in-differences design akin to Duflo's (2001) analysis of a school construction program in Indonesia. Our design is motivated by earlier studies finding few schooling impacts on youth who were offered the program at age 15 or later, past the critical transition between primary and secondary school (Parker and Todd, 2017). We confirm these findings in our data and thus use these older cohorts as a comparison group. We interact this cohort variation in program incidence with geographic variation in municipality program penetration during the Progresa's first phase of rollout across Mexico.

Using this difference-in-differences strategy, we find that exposure to greater program penetration before reaching the primary-to-secondary transition improves accumulated education, labor market outcomes, housing characteristics, durable goods ownership, and geographic mobility, primarily for women. Compared with those offered the program too late, women from early beneficiary cohorts in fully treated municipalities complete 1-1.6 additional grades of schooling, 15-20 percent of mean educational attainment. Women's labor market outcomes also improve, with exposure to full rollout increasing participation by 5-9 percentage points (21-38 percent of the mean), work for pay by 6-8 percentage points (39-48 percent of the mean), and labor earnings by roughly 40 percent of the mean. We interpret these labor market impacts as reflecting the benefits of additional education, possibly mediated by migration, which also rises with childhood exposure. Moving to household outcomes, we find positive effects on housing conditions and durable goods ownership, although these results may reflect either human capital or the direct benefits of greater parental wealth. For men, we find modest effects on a few outcomes-educational attainment, migration, and housing conditions-but most outcomes fail to show robust evidence of program impacts.

Because Progresa targeted more disadvantaged areas, our difference-in-differences design risks confounding from differential cohort trends between more and less disadvantaged areas. We address this concern in four ways. First, we restrict our sample to municipalities in the highest categories of the Mexican government's marginality classification, where rollout was most intense. 
Second, all of our models allow outcome differences between pre- and post-program cohorts to vary with cumulative municipal enrollment at the end of a second phase of rollout. As a consequence, identification requires parallel trends only between early- and late-rollout municipalities, rather than between early-rollout municipalities and all others. Third, as a robustness check, we estimate models that allow cohort trends to vary flexibly with initial marginality, measured at both the municipality and locality levels. Fourth, we assess pre-program trends by estimating event study models and running falsification checks using a census that took place seven years before rollout began. For women, we find that the estimates are stable across regression specifications and cannot be attributed to pre-existing trends. ${ }^{5}$ The results for men are less stable and less distinguishable from pre-existing trends.

The different results for men and women may point to Progresa as a driver of gender equality in the poorer parts of Mexico, but they may also partially reflect sample selectivity. Our main regression sample contains 16 percent fewer men than women. This gender imbalance raises questions about selectivity among young men, who emigrate (INEGI, 2009) and risk homicide (INEGI, 2019) at higher rates than young women. The gender imbalance is not associated with program exposure in our study cohorts, nor is cohort size, allaying concerns about selection directly on treatment. ${ }^{6}$ However, international migration and mortality may induce selection on treatment effects, in which the men with the largest potential gains from program exposure select out of the sample. As a consequence, we interpret the gender differences with caution.

Nevertheless, the gender differences are noteworthy in light of women's historically low status, education, and labor force participation in program areas. In Mexico's poorest states, we find that the closing of the gender gap in secondary school attainment coincided with the onset of Progresa. We estimate that the program can account for $1 / 3-1 / 2$ of this convergence. Gender parity in education was a secondary goal of Progresa: grant amounts were larger for girls than for boys, and mothers rather than fathers received the transfers. Our results suggest that Progresa achieved this secondary goal.

Beyond the literature on CCTs specifically, our results relate to a growing body of work on cash transfers more generally, including those that do not condition on child investment. Debates persist on the pros and cons of conditionality (Baird et al., 2013), but both forms of cash transfers are

\footnotetext{
${ }^{5}$ Results for women are also robust to controlling for political clientilism, school construction, and violence.

${ }^{6} \mathrm{We}$ also take several approaches to ensure that our results are not biased by internal migration.
} 
growing in popularity. Noting the limited evidence on their long-term consequences, Blattman et al. (2017) call for a redoubling of efforts to learn about the long run. In the case of unconditional transfers, long-run evidence for the next generation is also thin. In a developing country context, Araujo, Bosch, and Schady (2017) carry out a ten-year follow-up study of Ecuador's cash transfer program - in which transfers were unconditional, although some beneficiaries mistakenly thought they were conditional - finding mixed results on education and no significant effects on labor market outcomes. ${ }^{7}$ Some evidence is also available from the historical United States, where welfare programs for mothers (Aizer et al., 2016) and food stamp programs (Hoynes, Schanzenbach, and Almond, 2016) had a range of long-term benefits for individuals exposed as children.

Our findings add much-needed evidence on the long-run impacts of a popular anti-poverty policy. While the many studies on the short- and medium-run effects of Progresa and other CCT programs provide much guidance to policymakers, long-term follow-up on the next generation is crucial to assessing whether the programs are achieving the second of their dual goals: reducing poverty in future generations. A few recent studies finding smaller-than-expected effects of cash transfers in the longer term (e.g., Baird, McIntosh, and Oxler, 2018; Haushofer and Shapiro, 2018) have led to debate over their promise, but this debate concerns whether the effects of short-lived experimental programs are sustained in the few years after the end of operations. That question is conceptually distinct from ours, which deals with the effects of a long-lasting government program on the next generation. While studies of other programs are clearly needed, the results on Mexico's pioneering program are encouraging with respect to the potential of CCTs to reduce poverty in the next generation, particularly for women.

\section{Program Background}

\subsection{Rollout Patterns}

Progresa began operating in small rural communities in 1997, following a macroeconomic crisis in Mexico in 1995, and was part of a transition towards implementing targeted anti-poverty programs and eliminating general food subsidies. It quickly grew over time and at its peak covered six million families, about one quarter of all families in Mexico. While the program eventually expanded

\footnotetext{
${ }^{7}$ Baird, McIntosh, and Ozler (2018) also provide results for an unconditional treatment arm, finding no effect on schooling and a short-term effect on early marriage that disappears within two years of the program.
} 
into urban areas, it remained largely rural throughout, with about two-thirds of its household beneficiaries deriving from communities with less than 2500 inhabitants. Figure 1 shows the aggregate numbers of households who became beneficiaries in each year year since the program began. New enrollment activity was most intense during the first decade of the program, under the presidencies of Ernesto Zedillo and Vicente Fox, with clear troughs in presidential $(2000,2006,2012)$ and midterm $(2003,2009,2012)$ election years. These troughs, which reflect an anti-vote buying policy that prohibits social program expansion in the leadup to national elections, provide a rhythm to the rollout that is useful for our research design. The geographic component of our difference-in-differences design compares areas that enrolled households more intensively under Zedillo (1997-99) to those that enrolled households more intensively under Fox (2000-05).

The program was means tested, with both geographic and household-level targeting. The geographic targeting selected poor rural localities in part by using a locality-level marginality index, formed by taking the first principal component of socioeconomic aggregates from census data. Within selected localities, Progresa surveyed all households and then used discriminant analysis to distinguish eligible from ineligible households based on characteristics such as dwelling conditions, dependency ratios, ownership of durable goods, animals and land, and the presence of disabled individuals. Skoufias, Davis, and de la Vega (2001) compare the targeting algorithm with consumption- and geography-based alternatives and conclude that the program performed well in targeting the poorest.

Figure 2 documents how the marginality index related to the selection of localities during the two rollout phases that are key to our research design. On the horizontal axis is a locality's percentile rank in the distribution of the 1995 locality marginality index, which directly guided geographic targeting. On the vertical axis is the number of households in the locality that were newly enrolled during each phase, divided by the number of dwellings in the locality in $1995 .{ }^{8}$ The scatterplots represent the mean of the new enrollment ratio within each percentile bin, while the curves are local linear regressions. The vertical lines demarcate the five marginality categories designated by

\footnotetext{
${ }^{8}$ The marginality index and dwelling counts are constructed by the Mexican Population Council (CONAPO) based on the 1995 intercensal survey, which reported dwelling but not household counts at the locality level. The merge to Progresa's enrollment database is imperfect due to poorly-documented changes in locality identifiers and the suppression of CONAPO data for very small localities. After accounting for documented splits and merges, the enrollment database shows 82,648 localities with at least 1 household enrolled by the end of 2005 . We successfully merge 90 percent of these localities to the CONAPO data. Of the localities which do not merge, 78 percent have fewer than 10 households enrolled and all have fewer than 250, suggesting small populations. To construct Figure 2, we assume 0 enrollment for unmerged localities in the Conteo data and restrict the sample to localities with at least 10 dwellings.
} 
CONAPO (the Mexican Population Council), from "very low" to "very high" marginality.

During both rollout phases, new enrollment activity rose with the marginality index. Consistent with program protocol, Progresa targeted the top two marginality categories during the first phase of rollout, with percentile mean enrollment ratios ranging from 0.26 to 0.56 . By comparison, percentile means in the bottom two marginality categories were all below 0.02 during the first phase of rollout. The program became less geographically targeted in the second phase of rollout, but new enrollment ratios remained far higher in more marginalized localities.

Data constraints force us to use municipality-level rather than locality-level variation in our impact analysis. To visualize how the relationship in Figure 2 aggregates to this less granular geography, Figure 3 plots the new enrollment ratio against percentiles of the marginality index at the municipality level. ${ }^{9}$ The municipality-level enrollment ratio divides by the estimated number of households in 1997 (interpolated between the 1990 and 2000 censuses), and the municipality marginality index uses socioeconomic aggregates from the 1990 census. ${ }^{10}$ As in Figure 2, we plot percentile means and local linear regressions for each rollout phase, with vertical lines demarcating CONAPO's five marginality categories.

Similar to the locality-level patterns in Figure 2, the municipality-level patterns for both phases in Figure 3 reveal more intense rollout in more maginalized places. Two differences emerge, however. First, the municipality-level patterns are more gradual. Steep changes at the boundaries between marginality categories disappear due to aggregation. Second, differences between rollout phases are less stark in the municipality-level data. In Figure 2, 56 of the locality percentile bins have gaps between rollout phases of more than 10 percentage points; in Figure 3, only 15 of the municipality percentile bins have gaps exceeding this threshold. The greater overlap between municipalities with similar socioeconomic conditions but different rollout timing is useful for our difference-in-differences design, since municipalities with similar socioeconomic conditions may be more likely to follow parallel trends in potential outcomes.

\footnotetext{
${ }^{9}$ Appendix Figure A1 maps new enrollment ratios across municipalities in 1997-99 and 2000-05. Geographic patterns are broadly similar, with more intense enrollment in the poorer western and southern regions of Mexico.

${ }^{10}$ We use the 1990 rather than 1995 marginality index because it incorporates more data on socioeconomic conditions.
} 


\subsection{Age Structure of Benefits}

The program conditioned cash payments to families on children regularly attending school and on family members visiting health clinics for checkups. Program rules allowed students to fail each grade once, but if a student repeated a grade twice, the schooling benefits were discontinued permanently. The program also provided some additional subsidies for school supplies and a transfer linked to regular visits to health clinics. ${ }^{11}$ Children and youth aged 21 and younger were eligible to receive the school subsidies. Originally, the program provided grants only for children in grades 3-9, but in 2001, the grants were extended to grades 10-12. As shown in Appendix Table A1, grant sizes rose with grade, with discontinuous jumps between schooling levels. By the final year of high school, the grant amounted to roughly two-thirds of Mexico's minimum wage.

Existing evidence suggests that the program was particularly important for preventing dropout during the transition from primary to secondary school, between the 6th and 7th grades. The original evaluation of Progresa randomly assigned 506 communities to treatment and control groups. Eligible households in treatment communities began to receive benefits in 1998, while eligible households in control communities began in 2000. Studies of education impacts during the 18-month experiment show large enrollment effects at the transition between primary and secondary school (Schultz, 2004; Behrman, Sengupta, and Todd, 2005) and reductions in grade repetition in primary school (Behrman, Sengupta, and Todd, 2005). Few significant effects were observed for youth who had 6 or more years of schooling or were older than 15 at the program's start. In a non-experimental study with a longer follow-up, Behrman, Parker, and Todd (2011) find that beneficiary children aged 9-12 at the program's start accumulated nearly a grade of additional schooling relative to a matched comparison group not receiving benefits, while older cohorts experienced much smaller effects.

In short, previous studies of Progresa indicate large education gains for youth who had not yet reached the primary-to-secondary transition at rollout. Older youth saw no such gains, suggesting that this group—although technically eligible—was effectively too old; the program came too late to undo dropout. This cohort can serve as a comparison group for cohorts exposed at an earlier age.

\footnotetext{
${ }^{11}$ The program added a fixed monthly transfer to each individual over 70 in 2006, an additional fixed monthly benefit linked to (but not conditioned to)energy consumption in 2007 and a fixed monthly benefit per child aged 0 to 9 in 2008 .
} 


\section{Data and Methods}

\subsection{Data}

Our main outcomes dataset is the 10 percent sample from the Mexican Population Census of 2010, at which time early program beneficiaries were generally old enough to be out of school and in the adult labor force. ${ }^{12}$ We also draw on earlier 10 percent samples for supplementary analyses: from the 1990 census for falsification checks and from the 2000 census and 2005 intercensal survey for information on school enrollment and migration.

The 2010 census applied an extended questionnaire to all household members, providing information on schooling, labor market outcomes, household structure, geographic mobility, housing conditions, and durable goods ownership. For schooling, we analyze schooling level indicators as well as grades completed. For labor market outcomes, we consider indicators for labor force participation, wage work, and agricultural work, as well as monthly labor income. Due to lower labor force participation rates among women, we measure income in levels rather than logs and do not condition on participation. ${ }^{13}$ At the household level, we estimate effects on a housing conditions index, a durable goods ownership index, and total household monthly labor income per capita. Each index is defined as the first principal component of a vector of indicators relating to housing or durables ownership, standardized to have mean 0 and standard deviation 1 . For the housing index, we use indicators for having a dirt floor, modern roof, flush toilet, sewage, piped water, and electricity; for the durables index, we use indicators for having a car, mobile phone, computer, washer, refrigerator, TV, and hot water heater. To assess the role of geographic mobility, we consider indicators for urban residence in 2010 and for moving to a new state or municipality between 2005 and 2010. Most of these variables are available in the 1990 census, which we use for falsification checks.

Although Progresa relied on locality-based geographic targeting, the 2010 census allows us to track only municipality backward through an individual's residence history. As such, we merge the census data to Progresa enrollment data by municipality. To minimize concerns about endogenous migration, we would ideally rely on municipality of residence before the program. However, the 2010 census only tracks municipality backward to 2005, so we assign program exposure based on

\footnotetext{
${ }^{12}$ We use the 2010 census rather than the 2015 intercensal survey because the latter poses more risk for selection bias due to migration. The 2015 survey only provides municipal migration history back to 2010, and we find program effects on cross-municipal migration between 2005 and 2010.

${ }^{13}$ We measure incomes in 2010 Mexican pesos (worth 0.13 US\$ PPP in the same year [Penn World Table v9.1]).
} 
municipality of residence in that year. We discuss bias from pre-2005 migration in Section 3.3.

As a first step toward reducing concerns about differential trends between richer and poorer parts of Mexico, we only include municipalities classified as high or very high marginality in 1990, the year of the last pre-program census. To accommodate the formation of 41 new municipalities over our sample period, we aggregate municipalities into the smallest units with contiguous borders from 1990 to 2010, arriving at 1143 'master' municipalities with high or very high marginality, of a total of 2382 'master' municipalities nationwide. The program was operating in all high and very high marginality municipalities by the year 2000, so we measure the intensity of program penetration rather than an indicator for any penetration. ${ }^{14}$ To measure enrollment intensity over any given period, we divide new household enrollment during that period by the estimated number of households in the municipality in 1997 (interpolated between the 1990 and 2000 censuses).

Apart from municipality, birth cohort is the other basis for assigning program exposure. We form multi-year birth cohorts to avoid bias from differential age heaping. Appendix Figure A2 demonstrates the problem and our solution by plotting age histograms for ages 19-51 in sample municipalities. The single-year histogram reveals extensive age heaping, with disproportionate mass at ages ending in 0 and 5 . If this age heaping were endogenous to the program, then single-year cohort designations would be problematic for evaluating the program. Indeed, Appendix Figure A3 suggests that the tendency to misreport age declines with human capital: average education is lower among individuals reporting an age ending in 0 than among individuals reporting either of the neighboring ages. Consequently, we form three-year bins surrounding each multiple of 5 and form two-year bins between them, which leads to smoother density and conditional mean functions, as shown in Appendix Figures A2-A3. In the final sample, we only include bins with less than 10 percent still in school, leading us to drop 19-21 year-olds, among whom 18 percent were still in school.

\subsection{Design and Estimation}

Our identification strategy relies on two sources of variation: spatiotemporal variation in program rollout at the municipality level and cohort variation in the age at which children in eligible house-

\footnotetext{
${ }^{14}$ Variation in the proportion of beneficiaries enrolled over time across municipalities may be due to differences in the timing of the rollout of the program at the locality level or to differences in the proportion of households in selected localities who receive the program.
} 
holds were offered the program. We interact age eligibility with administrative information on the proportion of households receiving benefits in the municipality of residence.

Our definition of age eligibility must contend with the prevalence of grade repetition in Mexico. Mexican children can start secondary school as early as age 12, but due to grade repetition, the primary-to-secondary transition spans many ages. Appendix Figure A4 plots enrollment rates in each education level by age in sample municipalities in the 2000 census. Secondary education in Mexico is split into two levels, middle (grades 7-9) and high (grades 10-12). From ages 9-11 to 12-13 to $14-16$ to $17-18$, primary school enrollment drops from 96 to 67 to 17 to 3 percent; middle school enrollment peaks at 36 percent at ages 14-16. Based on these patterns, we treat cohorts aged 13 and younger in 1997 as 'fully exposed,' cohorts aged 16 and older in 1997 as 'not exposed,' and the cohort aged 14-15 in 1997 as 'partially exposed.' We omit the partially exposed group from our main estimations, but we include it in graphical event studies.

A typical approach to difference-in-differences estimation involves regressing an outcome on municipality fixed effects, cohort fixed effects, and the interaction of early program intensity with a cohort exposure indicator. This strategy requires that in the absence of rollout, cross-cohort trends would be parallel in municipalities more and less intensively treated at the start of the program. Because initial poverty predicts enrollment intensity, this assumption would be violated if, for example, initially poor municipalities tended to converge toward less poor municipalities across successive cohorts. As such, we modify the standard specification to ask whether, among municipalities with the same cumulative enrollment intensity at the end of the Fox administration (2005), those that saw more intensity during the Zedillo administration (1997-1999) experienced larger gains in early beneficiary cohorts. Thus, the spatial component of our design focuses on an early-versus-late comparison, rather than ever-versus-never. We reason that early and late municipalities with the same overall enrollment intensity are more likely to share trends than municipalities with different overall enrollment intensities.

This approach only requires us to include one additional covariate, the interaction of later cumulative program intensity with a cohort exposure indicator. For individual $i$ from municipality $m$ and birth cohort $t$, our baseline regression specification is:

$$
y_{i m t}=\beta\left(\text { enroll }_{m}^{1999} \times \text { post }_{t}\right)+\gamma\left(\text { enroll }_{m}^{2005} \times \text { post }_{t}\right)+\delta_{m}+\eta_{t}+\varepsilon_{\text {imt }}
$$


where $y_{\text {imt }}$ is an outcome; enroll $\tau_{m}^{\tau}$ measures the cumulative enrollment ratio by the end of year $\tau$ (1999 or 2005); post $t_{t}$ is an indicator for being younger than 14 in 1997; and $\delta_{m}$ and $\eta_{t}$ are municipality and cohort fixed effects, respectively. Cross-cohort trends that differentially affect municipalities with greater shares of eligible households load onto $\gamma$, while $\beta$ captures the effect of having greater enrollment intensity in the first rather than second phase of rollout.

To represent our results graphically, we also estimate an event study specification:

$$
y_{i m t}=\beta_{t} \text { enroll }_{m}^{1999}+\gamma_{t} \text { enroll }_{m}^{2005}+\delta_{m}+\eta_{t}+\varepsilon_{i m t}
$$

We report estimates of $\beta_{t}$ in a series of event study diagrams, normalizing $\beta_{t}$ to zero for the last unexposed cohort, aged 16-18 in 1997. To be consistent with the hypothesized age pattern of program impacts, the event studies should show limited trends in $\beta_{t}$ across the unexposed cohorts and positive changes in $\beta_{t}$ for the fully exposed cohorts. However, due to the small number of study cohorts, the event study model does not provide a strong test of parallel trends (Roth, 2020). We therefore emphasize the 1990 falsification check as a test of parallel trends.

We also augment equation (1) to further address concerns about parallel trend violations. Coupled with our focus on high and very-high marginality municipalities, our inclusion of enroll ${ }_{m}^{2005}$ goes a long way in addressing concerns about differential cohort trends across poorer and richer municipalities. However, Figure 3 shows that the relationship between the marginality index and enrollment ratios flattens slightly between the two rollout phases, suggesting that enroll $m^{2005}$ may not fully capture the unobserved heterogeneity that may be correlated with trends. As a robustness check to address this concern, we allow cohort effects to vary by a place's initial marginality. The discordance between our municipality-level research design and Progresa's locality-level geographic targeting strategy complicates the measurement of initial marginality. We take two approaches.

First, we include indicators for the municipality's percentile in the municipality marginality distribution, allowing the coefficients to vary by cohort:

$$
y_{\text {imt }}=\beta\left(\text { enroll }_{m}^{1999} \times \text { post }_{t}\right)+\gamma\left(\text { enroll }_{m}^{2005} \times \text { post }_{t}\right)+\sum_{p} \pi_{t}^{p} \mathcal{M}_{m}^{p}+\delta_{m}+\eta_{t}+\varepsilon_{\text {imt }}
$$

where $\mathcal{M}_{m}^{p}$ is an indicator for whether municipality $m$ falls in the $p^{\text {th }}$ percentile of the municipality marginality distribution. The coefficients $\pi_{t}^{p}$ vary by cohort $t$, so terms in the summation amount to 
interacting the percentile indicators with year indicators. This approach effectively absorbs the variation displayed in Figure 3, controlling for differential trends between more and less disadvantaged municipalities.

Second, we include shares of the municipality's population residing in localities at each percentile of the locality marginality distribution, again allowing the coefficients to vary by cohort. This approach partially captures the variation displayed in Figure 2, controlling for differential trends between municipalities with varying shares living in disadvantaged localities. To represent this variation visually, Figure 4 draws a heat map in which the vertical axis is the locality marginality percentile bin, the horizontal axis is the share of the municipality's population living in a locality at that percentile, and the color represents the new enrollment ratio. Consistent with Figure 2, enrollment ratios are higher in municipalities with greater shares of people living in marginalized localities. The pattern is stronger in the first phase of rollout. Adding the locality marginality shares to equation (4), we obtain:

$$
y_{i m t}=\beta\left(\text { enroll }_{m}^{1999} \times \text { post }_{t}\right)+\gamma\left(\text { enroll }_{m}^{2005} \times \text { post }_{t}\right)+\sum_{p} \pi_{t}^{p} \mathcal{M}_{m}^{p}+\sum_{p} \varphi_{t}^{p} \mathcal{L}_{m}^{p}+\delta_{m}+\eta_{t}+\varepsilon_{\text {imt }}
$$

where $\mathcal{L}_{m}^{p}$ is the share of municipality $m^{\prime}$ 's population residing in localities at the $p^{\text {th }}$ percentile of the locality marginality distribution. Here, $\beta$ captures the effect of the program on fully exposed individuals in early rollout municipalities relative to individuals in late rollout municipalities that had the same marginality percentile, the same shares of individuals living in disadvantaged localities, and the same cumulative enrollment in $2005 .^{15}$

Progresa targets the poor, so municipal poverty dynamics may partially drive the timing of enrollment intensity. In this case, differential changes in cohort outcomes between municipalities with differing enrollment intensities may reflect childhood exposure to poverty rather than Progresa. Equation (4) eliminates bias stemming from poverty dynamics that are correlated with initial conditions, but not from shocks. We focus on broad implementation phases rather than higher-frequency intervals partly to address this concern; the intensity of rollout over the course of each phase reflects idiosyncratic bureaucratic and programmatic considerations. Further, if residual poverty dynamics

\footnotetext{
${ }^{15}$ To shed light on the identifying variation, Appendix Table A2 reports the $R^{2}$ from regressions of enroll ${ }_{m}^{1999}$ on various combinations of the other covariates in equations (1) and (4). In sample municipalities, enroll $m_{m}^{2005}$ accounts for 65 percent of the variance of enroll ${ }_{m}^{1999}$. Adding $\mathcal{M}_{m}^{p}$ increases this statistic to 67 percent, and further adding $\mathcal{L}_{m}^{p}$ increases it to 75 percent.
} 
do play a role in the timing of enrollment intensity, they likely bias against finding positive program impacts. If Progresa tended to enter communities during shocks that increased poverty, then childhood exposure to the program would be associated with childhood exposure to adverse economic conditions. This reasoning suggests that our estimator produces a lower bound on the long-term benefits of the program. ${ }^{16}$

We interpret $\beta$ as an average dose response to rollout at the municipality level, rather than an average effect of childhood enrollment at the individual level. Two issues preclude the latter interpretation. First, our setup amounts to a "fuzzy differences-in-differences" design (de Chaisemartin and d'Haultfoeuille, 2018) with an unstable share of treated individuals in the control group. As such, even if program effects were private to enrollees, conventional methods could only recover an average individual treatment effect if early enrollees in early- and late-rollout municipalities had the same treatment effects on average. Second, program effects are unlikely to be private to enrollees. Using data from the original experimental evaluation of Progresa, Bobonis and Finan (2009) and Lalive and Cattaneo (2009) find that school enrollment and attendance rose in treatment communities even among children ineligible for the program, implying social spillovers. As such, $\beta$ is best interpreted as the effect of local program expansion on all children, eligible and ineligible, with its magnitude reflecting a move from no households enrolled to all households enrolled.

\subsection{Migration}

Migration, both internal and external, poses a threat to identification. If Progresa affected emigration from sample municipalities, then remaining individuals may be non-randomly selected, potentially biasing our estimates. While no research has investigated the program's long-term effects on migration, two studies on the initial years of the program provide conflicting evidence on shortterm effects, one suggesting more international migration (Angelucci, 2013) and one suggesting less (Stecklov et al., 2005). However, both studies find small impacts in absolute terms, with less than a 0.5 percentage point change in the probability of migrating to the United States.

To avoid bias from a migration response to childhood program exposure, our strategy requires that we assign program exposure to individuals according to their pre-program municipality of res-

\footnotetext{
${ }^{16} \mathrm{~A}$ counterargument is that the same forces lead older control cohorts to experience adverse economic conditions at labor market entry, potentially biasing our estimates upward.
} 
idence, not the current municipality of residence at the time of the 2010 census. As mentioned in Section 3.1, the census only allows us to 'return' migrants to their places of residence in 2005. Fully exposed cohorts may have had opportunities to migrate before 2005, principally during 2000-2005. However, data from the 2005 intercensal survey reveal low rates of inter-state migration during 2000-2005, lower than during either adjoining 5-year interval. Nationwide, only 3.5 percent of fully exposed cohorts reported different states of residence in 2000 and 2005. The intercensal survey did not collect data on intra-state migration, but our results for the post-2005 period show effects only on inter-state migration.To assuage any remaining concerns about endogenous migration, the Appendix reports a robustness check that assigns birth state average program exposure to individuals whose 2005 state of residence differs from their birth state.

Some risk of bias remains from international migration as well as intra-national migration in older cohorts. To assess potential selection from these channels, we test for differential changes in municipality cohort size between municipalities more intensively treated in the first and second phases of rollout. We estimate municipality cohort sizes in 2005 based on the migration histories in the 2010 census, and we then use the logarithms of the estimate as the outcome in a cell-level version of equation (2).

Appendix Figure A5 presents the resulting event study, revealing that cohorts aged 21-23 and up in 1997 experienced significantly higher growth in earlier rollout municipalities. In contrast, the cohort size differential between earlier and later rollout municipalities is stable across younger cohorts. Meanwhile, when we repeat the exercise for 1990 municipality of residence in the 1990 census, we find no differential changes in municipality cohort sizes. Because differential cohort growth is evident only after Progresa, these estimates are consistent with a migration response to the program. Progresa contemporaneously discouraged young adults from leaving program areas, perhaps because these areas became more appealing places to start a family. Due to these apparent migration effects among individuals in their twenties at the start of rollout, our analysis sample only includes individuals who were 20 or younger in 1997.

\subsection{Summary of Final Sample}

Our final sample consists of individuals who were aged 9-20 in 1997 and resided in high or very high marginality municipalities in 2005. Younger individuals are omitted due to high rates of continued 
school attendance, while older cohorts are omitted due to differential migration. Binning leads to five distinct cohorts, aged 9-10, 11-13, 14-15, 16-18, and 19-20 in 1997. Event studies use all five cohorts, while our main regressions omit the partially exposed cohort aged 14-15 in 1997.

Table 1 reports summary statistics by sex for the 2010 regression sample, which omits the partially exposed cohort. Most averages are similar for men and women, except in the domain of the labor market. For both sexes, cumulative municipal enrollment averaged 34 percent at the end of the first phase of rollout and 63-64 percent at the end of the second. Schooling outcomes slightly favor men, but both men and women average between 7 and 8 grades completed. In contrast, labor market outcomes differ substantially by sex, with men exceeding women in earnings, work participation, and wage work participation by factors of more than 2.5 on average. At the household level, however, men and women exhibit similar average economic wellbeing. They also migrate internally at similar rates, with 6 percent changing municipalities over the previous 5 years.

A notable difference between the male and female samples is the number of observations, with 16 percent more women than men. This sample size difference has two likely causes. First, men are more likely to migrate internationally (INEGI, 2009). The 2010 census asks respondents to list all household members who had departed for another country since 2005. In sample municipalities, men comprise 82 percent of household members from sample cohorts who departed for the US (and remain there). Second, homicide mortality surged among young Mexican men from 2006 onwards (INEGI, 2019). Either explanation suggests lower risk of bias from sample selectivity in our analyses of women have than our analyses of men.

\section{Results}

We separate our results into four sets of outcomes: education, labor market, household economic wellbeing, and migration. For each set of outcomes, we provide numerical and graphical representations of the results. For the former, Tables 2-5 report difference-in-differences estimates pooling cohorts into two exposure groups. For each outcome, we present four estimates for men and four for women: one each of equations (1), (3), and (4) in the 2010 census, and one of equation (1) in the 1990 census as a falsification check. ${ }^{17}$

\footnotetext{
${ }^{17}$ We do not estimate equations (3) and (4) in the 1990 census because the marginality percentiles were determined in or after 1990.
} 
For graphical representation of our results, Figures 5, 6, 8, and 9 report event study estimates based on equation (2). The figures plot the estimated coefficients on interactions between cohort indicators and the proportion of households enrolled between 1997 and 1999, along with 95 percent confidence intervals. These event study graphs complement our main results by presenting our identifying variation most transparently, at the cost of wider confidence intervals on the cohortspecific coefficients.

\subsection{Educational Outcomes}

We study four separate measures of education: completed grades, the proportion with some middle school completed, the proportion with some high school completed, and the proportion with some college completed. Table 2 reveals that program exposure before the critical primary-to-secondary transition has large, positive effects on completed years of education. The estimated coefficients indicate that full rollout in a municipality raises schooling in exposed cohorts by 1.0-1.6 years for women and 0.6-1 year for men. Compared to average education, 7.6 years for men and 7.3 for women, these effects correspond to 8-13 and 14-22 percent increases for men and women, respectively. The coefficients shrink as we model cohort trends more flexibly, suggesting that some part of the baseline difference in differences reflects convergence between high- and low-marginality areas. Supporting this interpretation, the falsification exercise yields positive but imprecise coefficients on grades completed for both men and women (0.67 and 0.53$)$, suggesting pre-existing differential trends between earlier and later rollout municipalities. However, the event study graphs discussed below do not show differential trends.

Which schooling levels account for these increases? For both men and women, Table 2 shows significant effects on the probabilities of accumulating at least one year of middle school and high school. The middle school impacts range from 23 to 30 percentage points for women and 13 to 16 percentage points for men: enormous when compared to sample-wide middle schooling rates (53 percent among men, 48 percent among women). For high school, the effects are large for women (16-17 percentage points) but small for men (3-9 percentage points and insignificant in the most demanding specification). In contrast, we find no significant effects on college enrollment. To visualize these effects grade by grade, Appendix Figure A6 estimates Progresa's impact on the unconditional probability of completing at least $x$ grades of schooling, plotting the coefficients against $x$ from 1 
to 15 . The coefficients are stable for grades within schooling levels, suggesting that once students are induced to enroll in the next level of schooling, they stay on until its conclusion. The falsification exercises for schooling levels based on the 1990 census are statistically insignificant, and the coefficients are small relative to the 2010 effects.

Figure 5 shows event study graphs for education, supporting our interpretation of Progresarelated gains. Beginning with grades of completed schooling, the estimated coefficients rise with program exposure for both men and women aged 9-13 in 1997, consistent with positive program impacts on education. The coefficients are flat for the unexposed cohorts, suggesting a lack of differential pre-program trends between municipalities with earlier and later enrollment intensity, although we reiterate the weakness of this test with just two pre-program cohorts. The partially exposed group, aged 14-15 in 1997, displays smaller but still positive gains for women and no differences for men relative to the unexposed group, aged 16 and over in 1997. The event study graphs for the proportion with some middle and high school show similar patterns, with the largest impacts for the fully exposed group, as well as little evidence of differential pre-program trends in the unexposed group. In the final panel of Figure 5, the event study coefficients for some college are completely flat across all cohorts, suggesting that childhood exposure to Progresa does not raise college attendance. Overall, the estimated education impacts represent substantial increases in attainment among individuals who grew up with Progresa, particularly women.

Our estimates are in the upper range of previous estimates. In early evaluation studies, Schultz (2004) and Behrman, Sengupta, and Todd (2005) simulated total schooling impacts, suggesting the long-run effect of the program to be 0.6-0.7 years of schooling, significantly lower than our estimate of 1.3 years. However, both studies assume no education effects after $9^{\text {th }}$ grade, whereas ours finds that the effects continue into high school. They also rely on impacts only in the first year of the program, potentially ignoring growth in impacts over time. Based on 5-year follow-up data on the original evaluation sample, Behrman, Parker and Todd (2011) estimate medium-term education effects of about one full year of schooling, more comparable to the long-term results obtained here.

\subsection{Labor Market Outcomes}

We now turn to the long-run impacts of Progresa on labor market outcomes, studying labor market participation, participation in paid and agricultural work, and labor earnings. The large increases 
in education documented in Table 2 may translate to improved outcomes in the labor market as the young adults in our sample enter the workforce. As discussed previously, while increased education is likely to be the principal vehicle for labor market effects, other mechanisms may also be at work. For example, due to program transfers, early beneficiaries may have consumed higher quality diets in childhood. Our research design cannot isolate these mechanisms, allowing us only to observe the overall effects of being in the exposed group in an earlier-rollout municipality.

Consistent with the large impact on female education relative to baseline, Table 3 reveals that Progresa also had large effects on female labor market outcomes. Against a participation rate of 24 percent, program impacts of full municipality rollout on labor force participation range from 5 to 9 percentage points, with larger estimates from the more demanding regression specifications. Virtually all of this impact is driven by increases in wage work, which increases 6 to 8 percentage points compared with a mean of 16 percent. Progresa also raises monthly labor earnings, with impacts ranging from 236 to 268 pesos (31-35 US\$ PPP in the same year), relative to a mean of 651 pesos (85 US\$). For labor force participation, wage work, and earnings, all estimates are significant at the 10 percent level, and all but three are significant at the 5 percent level. We observe no statistically significant effects of Progresa on participation in agricultural work for women.

The falsification checks and event study estimates for women's labor market outcomes suggest little role for differential cohort trends. In Table 3, estimates from the 1990 census are all insignificant and close to zero. In Figure 6, the event studies show post-program gains in earlier rollout municipalities for all labor market outcomes except agricultural work, although the coefficients are imprecisely estimated. Coefficients are positive for the fully exposed group, generally decline for the partially exposed group, and stay small for the unexposed group.

Table 3 demonstrates fewer labor market effects for men. The 2010 estimates are unstable across regression specifications, and for none of the outcomes are they significant across all three. The probability of working or receiving a wage does not change significantly. We do observe reductions in agricultural work as large as 11 percentage points, but we cannot reject that they are attributable by differential trends. Effects on labor earnings are positive but variable across the three specifications and statistically significant only in equation (4) without locality marginality percentile shares. ${ }^{18}$ The falsification exercise also yields a significant and positive coefficient on income, sim-

\footnotetext{
${ }^{18}$ The larger standard errors for men reflect their greater earnings dispersion.
} 
ilar in size to our coefficient estimates, raising the possibility that gains for men may be driven by convergence between poor and less poor areas. In Figure 6, the event studies for men's participation in any work and paid work are noisy, consistent with no clear evidence of effects on these outcomes. Those for agricultural work and labor earnings are more consistent with impacts, but the results from Table 3 push back against this interpretation.

To what extent can the earnings results be attributed to changes in labor force participation and the prevalence of paid work? Figure 7 plots effects on the complementary cumulative distribution of earnings for each sex separately. For a series of thresholds from 0 to 5000 pesos per month (in increments of 100), we estimate versions of equations (1) and (4) in which the dependent variable is an indicator for earnings exceeding the threshold. Consistent with an important role for female labor force participation, the results reveal that the largest change in the female earnings distribution is at the bottom: a shift from zero to positive earnings. For men, the largest shift in mass occurs more centrally in the distribution, although none of the estimated effects are statistically significant.

Placebo estimates using 1990 census data appear in Appendix Figure A7, finding no evidence of differential pre-program trends.

To summarize this section and the last, in a context of low female labor force participation and education, Progresa has led to striking growth in both areas for young adult women, as well as a significant increase in labor earnings. Male education increased by a lesser amount and men show fewer labor market effects, with no effects on participation in overall or wage work. Estimated effects on male labor earnings show an inconsistent pattern, but our falsification exercise was suggestive that any positive effects may be driven by convergence between poor and less poor areas.

Both the mean and the dispersion of earnings rise steeply with age and experience early in the lifecycle, so earning effects may grow as Progresa's early beneficiaries approach middle age. Additionally, productivity losses from lost experience due to schooling may fade over time. In fact, about 10 percent of our sample remains in school, so further work impacts may become apparent as these young adults enter the labor force.

\subsection{Household and Demographic Outcomes}

A key question is whether Progresa's labor market benefits translate to higher household income and consumption, which bear a more direct link to welfare. Although the census does not directly 
measure consumption, housing quality and durable goods indices offer proxies based on a subset of the consumption basket. Table 4 finds clear evidence of positive impacts on household housing and durable goods ownership for women. Effects range from 0.19 to 0.25 standard deviations for housing quality and from 0.15 to 0.23 standard deviations for durable goods ownership, significant at the 1 percent level in all specifications. Effects on total household labor earnings are small and statistically insignificant, perhaps reflecting intra-household substitution of labor. For men, we find a significant effect only for housing quality, with significance levels varying between 5 and 10 percent. The results for housing quality are especially likely to at least partially reflect parents' accumulation of a longer stream of transfers, rather than the labor market improvements we observe in our sample. This caveat is especially germane because over half of the fully exposed group continues to live with at least one parent.

Together with the event studies in Figure 8, the evidence in Table 4 suggests that differential cohort trends are unlikely to explain the positive results for household economic wellbeing, at least for women. First, placebo coefficients using the 1990 census are small and insignificant for housing quality and household earnings; the 1990 census did not collect data on durables ownership. Second, the 2010 results are robust across specifications. Third, the event studies for women reveal no significant difference in pre-program trends between early and late municipalities, and a stark, significant post-program gap. The event study for the men's housing index is difficult to distinguish from differential trends, although none of the coefficients are significantly different from zero.

Impacts on these household-level economic outcomes are inter-related with how the program affects household size, parental coresidence, marriage, and fertility, so we also analyze these outcomes in Appendix Table A3. We find no effects on any of these outcomes among women but do find decreases in parental coresidence among men, ranging from 11 to 13 percentage points. The decline in parental coresidence presumably reduces household wealth, so the effects on housing conditions and durable goods may be a lower bound for men.

Although we find no effects on the probability of being married, marriage markets may still mediate the household results through changes in matching outcomes. Thus, we analyze spousal characteristics among married individuals in Appendix Table A4, finding that greater early program exposure is associated with significantly higher spousal work and education for men and higher spousal earnings for women. These results require cautious interpretation because our young sam- 
ple's low marriage rate (less than 50 percent in the fully exposed group) raises concerns about sample composition. Nevertheless, they suggest that Progresa's effects on household economic outcomes may be partly mediated by the marriage market.

Geographic mobility may be an important channel for program impacts on labor market outcomes. Table 5 shows significant 6-10 percentage point increases in cross-municipal and cross-state migration (over the previous five years) and urban residence. Effects on intra-state migration are small and insignificant, however, suggesting that the cross-municipal effects primarily derive from cross-state migration. The migration effects are larger than the average propensity to migrate, which is 6 percent for cross-municipal migration and 4 percent for cross-state migration. Both the 1990 falsification checks and the event studies in Figure 9 suggest that differential trends do not explain the positive results. ${ }^{19}$

Taken together, these results point to positive effects on household economic status for women and to a lesser extent for men, which cannot be explained by changes in living arrangements but may be partly explained by changes in spousal characteristics. While Progresa did not affect the probability of being married, it does appear to have altered spousal characteristics in some dimensions. The results on geographic mobility suggest that Progresa's effects may also be partly mediated by migration from depressed rural areas to more economically vibrant urban areas.

\section{Sensitivity Analyses}

Throughout the analysis, we have reported three specifications, the first controlling for cumulative enrollment enroll $_{m}^{2005}$, the second adding municipality marginality percentile dummies, and the third adding locality marginality percentile shares. These three specifications broadly provide evidence of robustness to controlling for differential trends by key determinants of program rollout. For added evidence, the Appendix reports additional sensitivity analyses for key outcomes, changing the rule for assigning program exposure to out-of-state migrants, including additional controls for municipal poverty, and controlling for the potentially confounding roles of politics, school construction, and violence.

\footnotetext{
${ }^{19}$ Because the 1990 census did not collect data on intra-state migration, falsification checks are only possible for crossstate migration and urban residence. We find a significant placebo effect for male urban residence, but it has the opposite sign of the 2010 estimates.
} 
The first sensitivity analysis involves the way we assign program exposure to migrants. So far, our strategy has been to use the municipality of residence in 2005. However, some individuals in our sample were born in a different state from where they lived in 2005, and where these migrants resided in the late 1990s is unclear. As an alternative to our main strategy, we assign these migrants state-level enrollment ratios based on their states of birth. Additionally, because it is not possible to determine whether these individuals were born in high or very high marginality municipalities (an inclusion criterion for our sample), we add to the sample those migrants who were not living in high or very high marginality municipalities in 2005 but were born in states in which the average marginality index of the state exceeds the municipality threshold for high/very-high status. The state-level assignment rule for out-of-state migrants makes municipality fixed effects impossible, so we instead include the main effects of cumulative enrollment in 1999 and 2005. As reported in Appendix Table A5, this alternative approach leads to small variations in the estimated effects, but significance levels are similar, and the overall conclusions are unchanged.

The remaining robustness checks return to the original specifications and assignment rules but add covariates to deal with concerns about confounding from poverty, politics, school construction, and violence. In Appendix Tables A6 (for men) and A7 (for women), we reproduce the main results in the first three columns and then address each concern in an additional specification in columns 4 through 7 . In column 4 , we interact post $t_{t}$ with the nine components of the municipality marginality index to absorb any potential remaining differential cross-cohort changes driven by variation in measured initial poverty conditions. In column 5, we address the concern that municipalities with a history of supporting the Institutional Revolutionary Party (PRI, which was in power until 2000) might have received beneficial treatment during the early phase of rollout. To do so, we interact post $_{t}$ with the municipality's PRI vote share in the 1994 presidential election. In column 6, we consider whether a school construction program that began in the mid-1990s can explain our estimated effects of Progresa, interacting post $t_{t}$ with the number of new schools per capita in 1995-2000 and 2000-2005. In column 7, we assess whether the surge in drug-related violence after 2006 biases our results, interacting post $_{t}$ with the change in the municipality homicide rate from 2006 to 2010. In all four cases, the new covariates do not appreciably change the point estimates or significance levels. 


\section{Discussion}

We find clear evidence that childhood exposure to Progresa had lasting economic benefits for women, but the evidence on men is weaker and less conclusive. These findings beg two follow-up questions. First, do the benefits to women by themselves exceed the costs of the program? Second, how have program impacts influenced gender inequality in the poorest parts of Mexico?

\subsection{Implications for Benefit/Cost Ratios}

While several previous studies of Progresa have simulated benefit/cost analyses based on initial education impacts under varying assumptions regarding the returns to schooling (Behrman, Sengupta and Todd, 2005; Behrman, Parker and Todd, 2011), our results allow us to use actual earnings impacts. Given our inconclusive results for men, we calculate a lower bound for the benefit/cost ratio, asking whether the female earnings impacts, if sustained over the lifecycle, are large enough to outweigh the cost of rolling out the program in the early period, 1997-2000. In the spirit of finding a lower bound, we rely on our smallest estimated earnings impacts and assume no earnings growth over the lifecycle. Also in the spirit of a lower bound, we include program costs for both sexes, despite restricting program benefits to one sex. We express all monetary values in 2010 Mexican pesos (worth 0.13 US\$ PPP in the same year [Penn World Table v9.1]) and discount all streams to the start of the program at a 2 percent rate.

For benefits, we compute the aggregate effect of early (pre-2000) rollout on aggregate lifetime earnings for women in the early beneficiary cohort, aged 9-13 in 1997. The smallest estimated effect of full rollout on female earnings is 236 pesos per month, or 2832 pesos per year. Assuming that cohort members exit school age 7 years after the start of the program and may subsequently work for 45 years, this impact translates to a discounted lifetime impact of 72,706 pesos per woman. Multiplying by early program exposure in the 2010 census, we calculate that Progresa raised aggregate lifetime earnings by 26.4 billion pesos among women from in the early beneficiary cohort. ${ }^{20}$

We account for two types of program costs: opportunity costs of lost work and direct costs. For the former, we assume that an additional year spent in school implies 10 months of lost earnings. For

\footnotetext{
${ }^{20}$ Because our program expenditure data do not disaggregate by municipality, we estimate nationwide benefits and costs. We assume that our impact estimates for high and very high marginality municipalities also apply to lower marginality municipalities.
} 
a lower bound on the benefit-cost ratio, we rely on upper bound estimates of this opportunity cost. Our largest estimated impacts of full rollout on the probability of completing any middle school are 16.3 percentage points for men and 30.2 percentage points for women. For high school, the corresponding impacts are 8.8 and 17.0 percentage points, respectively. We estimate potential earnings during school age using the 2000 census. Weighted by early program exposure, male and female dropouts of middle school age (13-15) earned 739 and 170 pesos per month on average; dropouts of high school age (16-18) averaged 1159 and 346 pesos. Assuming minimal dropout within schooling level (consistent with Appendix Figure A6) and multiplying by early program exposure in the 2010 census, we calculate 5.4 billion pesos in discounted lost earnings for early beneficiary cohorts. Note that the lost earnings are mostly men's, while the benefits in our calculations accrue only to women.

For the direct costs of the program, we have access to annual program spending by category. We begin with the discounted sum of transfers in the early period, from 1997 to 2000. Data from Coady (2000) indicate 11.6 billion pesos of education transfers and 11.6 billion pesos of health transfers during this period. Our research design evaluates a component of Progresa most closely linked with secondary school transfers, which directly disincentivize dropout at the primary-to-secondary transition. However, to be conservative, we also include primary school transfers and health transfers, which may have contributed to our results by raising household incomes. ${ }^{21}$ Following Behrman, Parker, and Todd (2011) and Dhaliwal et al. (2012), we do not include the transfers as direct costs because they are likely to be at least as valuable to beneficiary families (who are poor) as they are to taxpayers. Instead, we use them to estimate administrative costs (of transferring benefits, conditionality, and targeting), private costs, and the deadweight loss of raising taxes to pay for the program. For administrative and private costs, we rely on Coady's estimates of 0.089 and 0.024 pesos per peso transferred, respectively. For deadweight loss, we do not have estimates of the marginal cost of public funds (MCPF) in Mexico, so we report results for a range of values. ${ }^{22}$

Despite our conservative assumptions, the earnings benefits to women far exceed the overall costs of early program rollout. Auriol and Warlters (2012) estimate the average MCPF in 38 African countries to be 1.2. At this value, the lower bound on the benefit-cost ratio is 2.0. If we instead rely

\footnotetext{
${ }^{21}$ We exclude direct expenditures on nutritional supplements and health consultations, which do not plausibly play a role in our results. We also exclude post-2000 continuing transfers to students still enrolled because of pre-2001 exposure, since we cannot distinguish among post-2000 transfer recipients.

${ }^{22}$ Due to the ambiguity of the marginal cost of public funds, Hendren (2016) suggests the marginal value of public funds as an alternative for welfare analysis. We lack the data to estimate fiscal externalities so cannot compute it.
} 
on the benchmark of 1.4 that Olken (2007) applies to Indonesia, the lower bound is 1.5.

\subsection{Implications for Gender Equality}

Early program documents stated: "Progresa seeks to improve the condition of women and empower the decisive role they play in family and community development" (Adato and Roopnaraine 2010). What was Progresa's role in closing Mexico's gender gaps across successive birth cohorts? In our cross-sectional dataset, age effects limit our ability to answer this question for economic outcomes, so we focus on educational attainment, which changes little in adulthood.

Until recently, women lagged behind men in secondary school attainment, particularly in poor, rural areas. To illustrate this pattern, Appendix Figure A8 plots long-term cohort trends in the rate of completing any secondary school by sex, separately for individuals born in higher- and lowermarginality states. ${ }^{23}$ For the cohort born around 1960 (age 36-38 in 1997), men's secondary attainment exceeded women's by 9.0 percentage points in higher marginality states and by 7.3 percentage points in lower marginality states. The gender gap then declined as men's educational progress slowed more than women's amidst economic crisis and budget cuts to education in the 1980s, so that the cohort born around 1975 (age 21-23 in 1997), the gender gap had shrunk to 4.5 percentage points in higher marginality states and disappeared altogether in lower marginality states. After this reduction, the gap in higher marginality states held steady across a decade and a half of birth cohorts, only to finally close in the Progresa generation. Between the last unexposed cohort (age 16-18 in 1997) and the youngest exposed cohort (age 9-10 in 1997) in our sample, the gender gap fell from 5.5 to 1.2 percentage points.

To what extent can we attribute this cross-cohort gender convergence to Progresa? Program data indicate that Progresa enrolled 15.3 percent of households in higher-marginality states in the first phase of rollout. Multiplying this enrollment ratio by the gender difference in program impacts, we calculate that program exposure shrank the gender gap in secondary school attainment by 1.5-2.1 percentage points. We conclude that Progresa can account for $1 / 3-1 / 2$ of this closing of the gender gap in the poorer parts of Mexico.

\footnotetext{
${ }^{23}$ We plot trends by state of birth instead of municipality of residence to avoid migration concerns.
} 


\section{Conclusions}

Conditional cash transfer programs began two decades ago, transforming anti-poverty policy around the world. Their linkage of payments to human capital investment had the dual goals of alleviating current poverty and reducing poverty in the next generation. While previous studies have found contemporaneous education and health benefits for children from beneficiary households, little research has addressed whether these changes improve the lives of these children when they reach adulthood. Whether the benefits of CCTs flow intergenerationally has remained an open question.

This paper provides new evidence that the intergenerational benefits of CCTs may be substantial. We estimate the long-term effects of Mexico's flagship program Progresa on the educational, labor market, household, and demographic outcomes of young adults who effectively grew up with the program. The results show large effects on the next generation's completed education, work, earnings, and household economic status, particularly for women. Before Progresa, women's labor force participation was extremely low in its original communities, as was their status in the household (Attanasio and Lechene, 2002). Relative to average outcomes in pre-program cohorts, the estimated effects of full rollout on female labor force participation range from 21 to 38 percent, and the estimated effects on female labor earnings are about 40 percent. Women also experience large increases in urban residence and cross-municipal migration, suggesting that geographic mobility may play a role in these impacts.

Men exhibit more nuanced results, with smaller education effects and fewer labor market effects. While we cannot reject that any observed male income gains reflect convergence between poor and less poor areas we do find significant decreases in agricultural work, consistent with some improvement in labor market conditions. For both sexes, we observe improvements in housing conditions and durable goods ownership, although these results may reflect greater human capital, greater parental wealth, or both.

These results are encouraging for the long-term prognosis of children from households receiving CCTs, particularly girls. Progresa significantly contributed to the closing of the education gender gap in Mexico's poorer states. Furthermore, the earnings impacts on young adults, many of whom no longer live with their parents, are unlikely to disappear when their parents stop receiving cash transfers. Similar reasoning applies for housing conditions and durable goods. As a consequence, 
these impacts are likely to represent permanent increases in wellbeing due to Progresa. In fact, our benefit/cost analysis finds that the female earnings gains, if sustained over the lifecycle, can by themselves pay for program costs.

Nevertheless, further work is needed, including long-term follow-up studies on other countries' CCT programs. For Progresa, further studies following youth beneficiaries past their early twenties would be useful, as would studies incorporating migrants to the United States. The larger effects we estimate for women may in fact be partially driven by greater selectivity of males from international migration and mortality. On the other hand, early studies including Schultz (2004) and Behrman, Sengupta and Todd (2005) demonstrate greater initial education enrollment effects on girls than boys, so our findings may simply demonstrate that longer term effects of Progresa are, in fact, greater for women than men.

Our analysis does not directly speak to the debate over whether cash transfers to poor families should be conditional (Baird et al., 2013). At the same time, for conditional transfers to be preferable to unconditional transfers, they must at a minimum improve the lives of children, who are the sole targets of conditionality. Short-run benefits like increases in school enrollment do not meet this standard on their own, unless one views enrollment as having intrinsic rather than instrumental value. As a result, our evidence of long-run benefits to childhood beneficiaries provides a necessary, though not sufficient, input to the design of anti-poverty programs.

\section{References}

Adato, M., and T. Roopnaraine. 2010. “Women's Status, Gender Relations, and Conditional Cash Transfers." In M. Adata and J. Hoddinott, eds., Conditional Cash Transfers in Latin America. Baltimore: Johns Hopkins University Press.

Angelucci, M. 2015. "Migration and Financial Constraints: Evidence from Mexico." Review of Economics and Statistics 97(1): 224-228.

Aizer, A., S. Eli, J. Ferrie, and A. Lleras-Muney. 2016. “The Long-Run Impact of Cash Transfers to Poor Families." American Economic Review 106(4): 935-971.

Araujo, M. Caridad, M. Bosch, and N. Schady. 2017. “Can Cash Transfers Help Households Escape an Inter-Generational Poverty Trap?" In C.B. Barrett, M.R. Carter, and J.P. Chavas, eds., The Economics of Asset Accumulation and Poverty Traps. Chicago: University of Chicago Press.

Attanasio, O.P., and V. Lechene. 2002. "Tests of Income Pooling in Household Decisions." Review of 
Economic Dynamics 5: 720-48.

Auriol, E., \& Warlters, M. 2012. "The Marginal Cost of Public Funds and Tax Reform in Africa." Journal of Development Economics 97: 58-72.

Baird, S., C. McIntosh, and B. Ozler. 2019. “When the Money Runs Out: Do Cash Transfers Have Sustained Effects on Human Capital Accumulation." Journal of Development Economics 140: 169-185.

Baird, S., F.H.G. Ferrerira, B. Ozler, and M. Woolcock. 2013. “Relative Effectiveness of Conditional and Unconditional Cash Transfers for Schooling Outcomes in Developing Countries: A Systematic Review." Campbell Systematic Reviews 2013(8).

Barham, T., K. Macours, and J.A. Maluccio. 2017. "Are Conditional Cash Transfers Fulfilling Their Promise? Schooling, Learning, and Earnings After 10 Years." Mimeo, Paris School of Economics.

Barham, T., K. Macours, and J.A. Maluccio. 2018. “Experimental Evidence of Exposure to a Conditional Cash Transfer During Early Teenage Years: Young Women's Fertility and Labor Market Outcomes." Discussion Paper Series Number 13165 CEPR.

Barrera-Osorio, F., L.L. Linden, and Juan Saavedra. Forthcoming. "Medium- and Long-term Educational Consequences of Alternative Conditional Cash Transfer Designs: Experimental Evidence from Colombia." American Economic Journal: Applied Economics.

Behrman, J.R., P. Sengupta, and P.E. Todd. 2005. "Progressing through PROGRESA: An Impact Assessment of a School Subsidy Experiment." Economic Development and Cultural Change 54: 237276.

Behrman, J.R., S.W. Parker, and P.E. Todd. 2009. "Medium-Term Impacts of the Oportunidades Conditional Cash Transfer Program on Rural Youth in Mexico." In S. Klasen and F. Nowak-Lehmann, eds., Poverty, Inequality, and Policy in Latin America. Cambridge, Massachussets: MIT Press, pp. 219-270.

Behrman, J.R., S.W. Parker, and P.E. Todd. 2011. Do Conditional Cash Transfers for Schooling Generate Lasting Benefits? A Five-Year Follow-up of PROGRESA/Oportunidades." Journal of Human Resources 46(1): 93-122.

Blattman, C., M. Faye, D. Karlan, P. Niehaus, and C. Udry. 2017. "Cash as Capital." Stanford Social Innovation Review Summer.

Bobonis, G., and F. Finan. 2009. "Neighborhood Peer Effects in Secondary School Enrollment Decisions." Review of Economics and Statistics 91 (4): 695-716.

Bobonis, G.J. 2011. "The Impact of Conditional Cash Transfers on Marriage and Divorce." Economic Development and Cultural Change 59(2): 281-312.

Cahyadi, N., R. Hanna, B.A. Olken, R.A. Prima, E. Satriawan, amd E. Syamsulhakim. 2020. "Cumulative Impacts of Conditional Cash Transfer Programs: Experimental Evidence from Indonesia." American Economic Journal: Economic Policy 12(4): 88-110.

Coady, D.P. 2000. "The Application of Social Cost-Benefit Analysis to the Evaluation of PROGRESA." International Food Policy Research Institute. 
Dhaliwal, I., E. Duflo, R. Glennerster, and C. Tulloch. 2013. “Comparative Cost-Effectiveness Analysis to Inform Policy in Developing Countries: A General Framework with Applications for Education." In P. Glewwe, ed., Education Policy in Developing Countries. Chicago: University of Chicago Press, pp. 285-338.

De Chaisemartin, C., and X. d'Haultfoeuille. (2018). “Fuzzy Differences-in-Differences." Review of Economic Studies 85(2): 999-1028.

Duflo, E. 2001. "Schooling and Labor Market Consequences of School Construction in Indonesia: Evidence from an Unusual Policy Experiment." American Economic Review 91(4): 795-813.

Fiszbein, A., and N.R. Schady. 2009. Conditional Cash Transfers: Reducing Present and Future Poverty. Washington, DC: World Bank.

Haushofer, J., and J. Shapiro. 2018. "The Long-Term Impact of Unconditional Cash Transfers: Experimental Evidence from Kenya." Working Paper, Princeton University.

Hendren, N. (2016). “The Policy Elasticity." Tax Policy and the Economy 30(1): 51-89.

Hoynes, H., D.W. Schanzenbach, and D. Almond. 2016. "Long-Run Impacts of Childhood Access to the Safety Net. American Economic Review 106(4): 903-934.

INEGI. (2009). Migración internacional captada a través de la Encuesta Nacional de Ocupación y Empleo 2006-2010. Online: https://rb.gy/2pa4tj.

INEGI. (2019). Patrones y tendencias de los homicidios en México. Online: https://rb.gy/e2yd1p

Kugler, A., and I. Rojas. 2018. "Do CCTs Improve Employment and Earnings in the Very LongTerm? Evidence from Mexico." NBER Working Paper 24248.

Lalive, R., and M. Cattaneo. 2009. "Social Interactions and Schooling Decisions." Review of Economics and Statistics 91: 457-77.

Molina Millán, T., K. Macours, J.A. Maluccio and L. Tejerina. 2018. “Experimental Long-term Effects of Early Childhood and School-age Exposure to a Conditional Cash Transfer Program." Working Paper.

Muralidharan, K., and P. Niehaus. 2017. "Experimentation at Scale." Journal of Economic Perspectives 31(4): 103-24.

OECD. 2013. PISA In Focus: What Makes Urban Schools Different. Paris: Organisation for Economic Co-operation and Development.

Olken, B.A. (2007). "Monitoring Corruption: Evidence From a Field Experiment in Indonesia." Journal of Political Economy 115(2): 200-249.

Parker, S., and P. Todd. 2017. "Conditional Cash Transfers: The Case of Progresa / Oportunidades." Journal of Economic Literature 55(3): 866-915.

Roth, J. 2020. "Pre-test with Caution: Event-study Estimates After Testing for Parallel Trends." Working Paper. 
Rendall, M., and S. Parker. 2014. "Two Decades of Negative Educational Selectivity of Mexican Migrants to the United States." Population and Development Review 40(3): 421-446.

Rodríguez-Oreggia, E., and S. Freije. 2012. "Long Term Impact of a Cash-Transfers Program on Labor Outcomes of the Rural Youth in Mexico." CID Working Paper 230.

Sanchez Chico, A., K. Macours, J.A. Maluccio and M. Stampini. (2020). "Impacts on School Entry of Exposure Since Birth to a Conditional Cash Transfer Programme in El Salvador." Journal of Development Effectiveness 12(3): 187-21.

Schultz, T.P. 2004. "School Subsidies for the Poor: Evaluating a Mexican Strategy for Reducing Poverty." Journal of Development Economics 74(1): 199-250

Skoufias, Emmanuel., Benjamin Davis, and Sergio de la Vega. 2001. “Targeting the poor in Mexico: evaluation of the selection of beneficiary households into PROGRESA", World Development 29: 19691984.

Skoufias, E. and S. Parker. 2001. "Conditional Cash Transfers and their Impact on Child Work and School Enrollment: Evidence from the PROGRESA program in Mexico". Economia 2(1): 45-96.

Stecklov, G., P. Winters, M. Stampini, and B.Davis. 2005. "Do Conditional Cash Transfers Influence Migration? A Study Using Experimental Data from the Mexican PROGRESA Program." Demography 42: 769-790. 
Figure 1: Number of New Households Enrolled Per Year, Nationwide

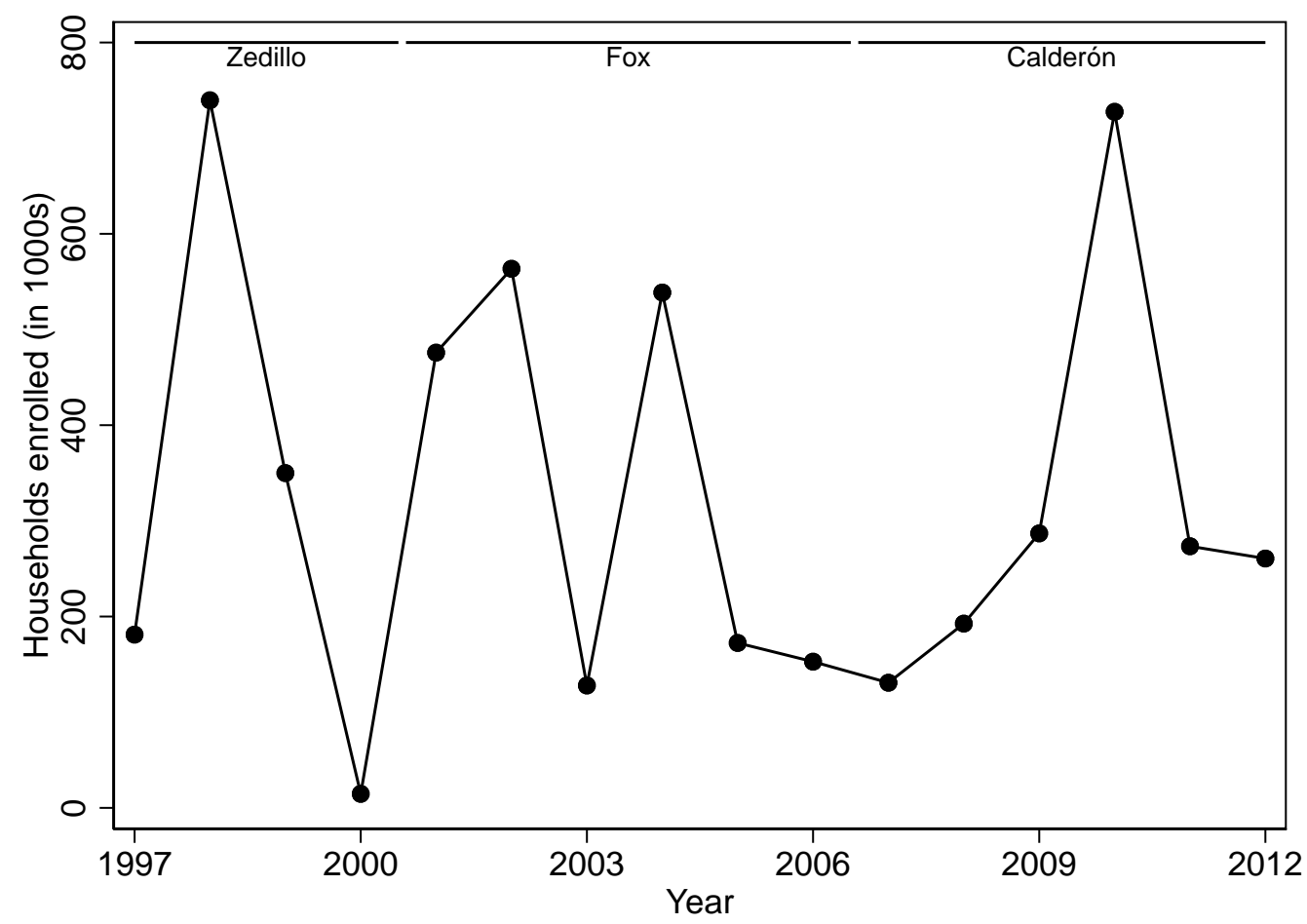

Note: Presidential elections occurred in 2000, 2006, and 2012; midterms occurred in 1997, 2003, and 2009. 


\section{Figure 2: Locality Enrollment Ratio vs. Locality Marginality Percentile}

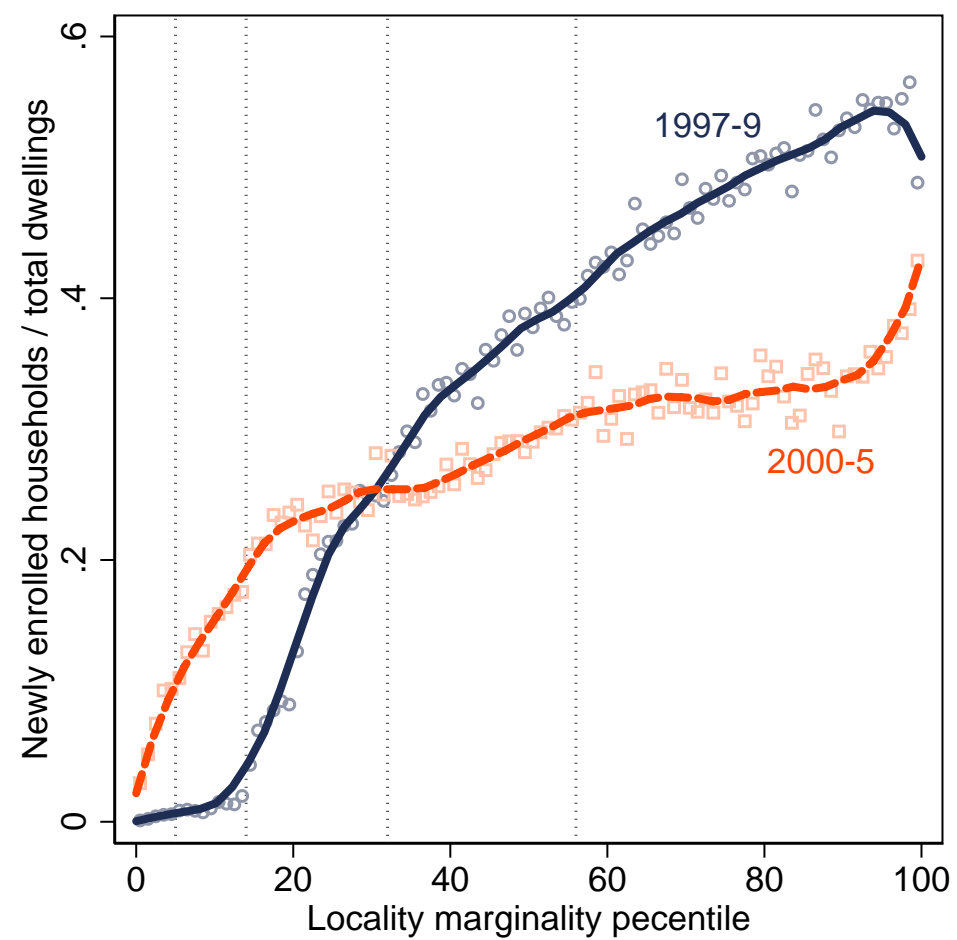

Note: Curves are local linear regressions with bandwidths of 2.5; each scatter point represents a 1-point bin. Sample includes 58,221 localities with at least 10 dwellings in 1995; see footnote 3 for sample construction details. The enrollment ratio is the count of new households enrolled divided by the number of dwellings in the locality in 1995. The locality marginality index, constructed by CONAPO using living conditions data from the 1995 intercensal survey, directly guided program rollout. Vertical lines represent cutoffs between marginality categories: very low, low, medium, high, and very high. 


\section{Figure 3: Municipality Enrollment Ratio vs. Municipality Marginality Percentile}

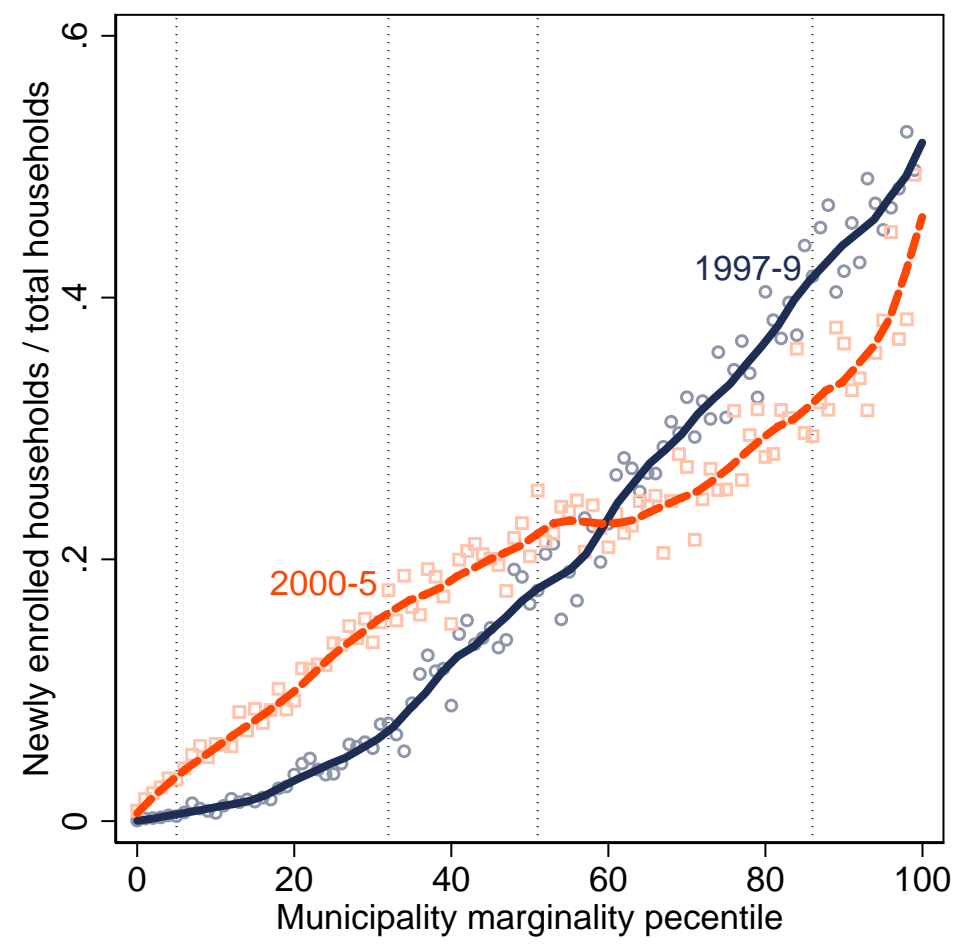

Note: Curves are local linear regressions with bandwidths of 2.5; each scatter point represents a 1-point bin. The enrollment ratio is the count of new households enrolled divided by the estimated number of households in the municipality in 1997. The municipality marginality index, constructed by the Mexican government using living conditions data from the 1990 census, did not directly guide program rollout. To accommodate the formation of 41 new municipalities over our sample period, we aggregate municipalities into the smallest units with contiguous borders from 1990 to 2010. Vertical lines represent cutoffs between marginality categories: very low, low, medium, high, and very high. 
Figure 4: Municipality Enrollment Ratio vs. Locality Marginality Share

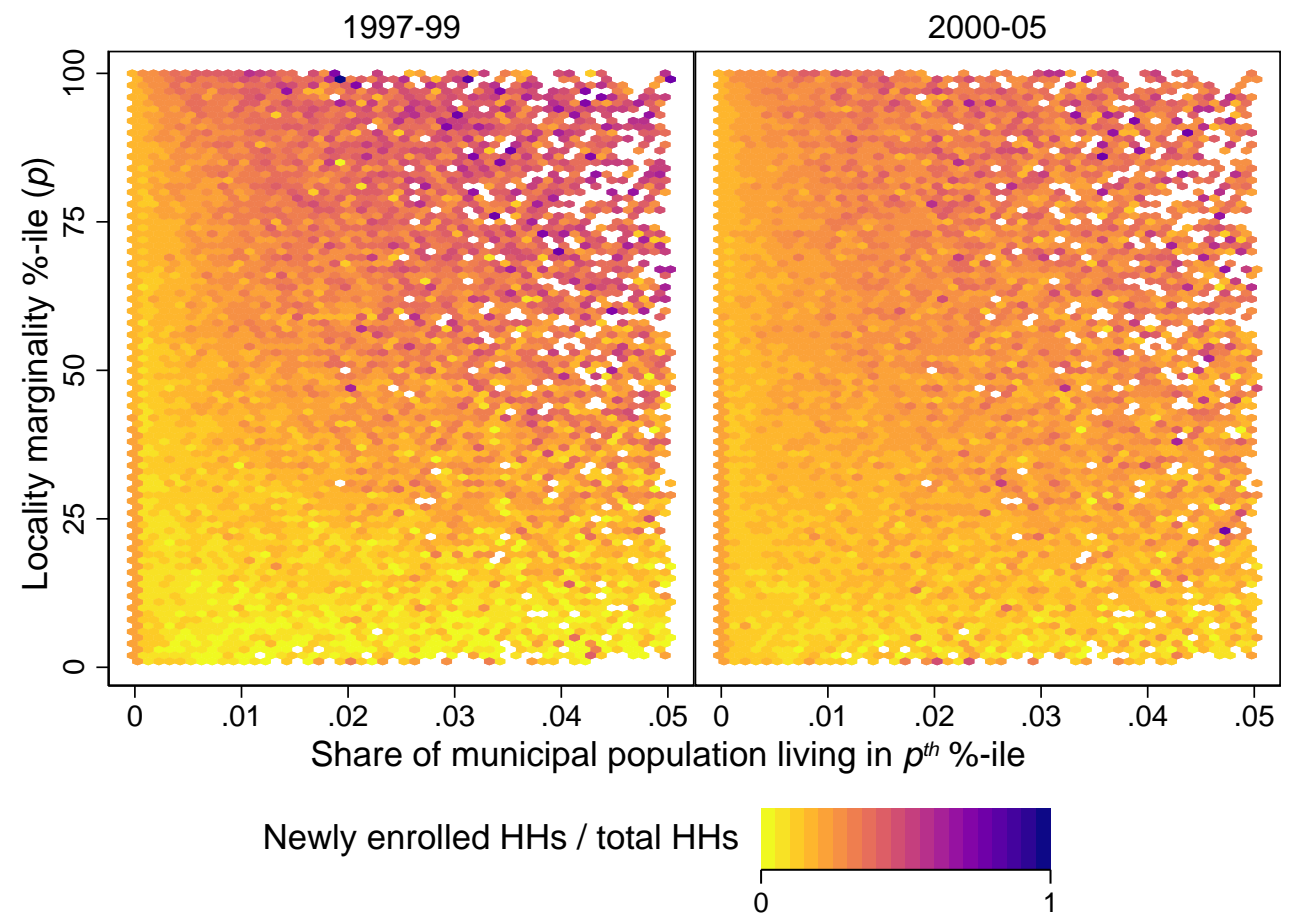

Note: The unit of observation is the municipality. Each hexagon is $1 / 10$ percentage points $(0.001)$ wide and 1 percentile point tall. White hexagons have no data. The enrollment ratio is the count of new households enrolled divided by the estimated number of households in the municipality in 1997 . The locality marginality index, constructed by the Mexican government using living conditions data from the 1995 intercensal survey, directly guided program rollout. To accommodate the formation of 41 new municipalities over our sample period, we aggregate municipalities into the smallest units with contiguous borders from 1990 to 2010. For each percentile bin of the locality marginality index, the heat plot displays how the enrollment ratio varies with the share of the municipal population living in a locality in that percentile bin. 


\section{Figure 5: Event Studies for Education}

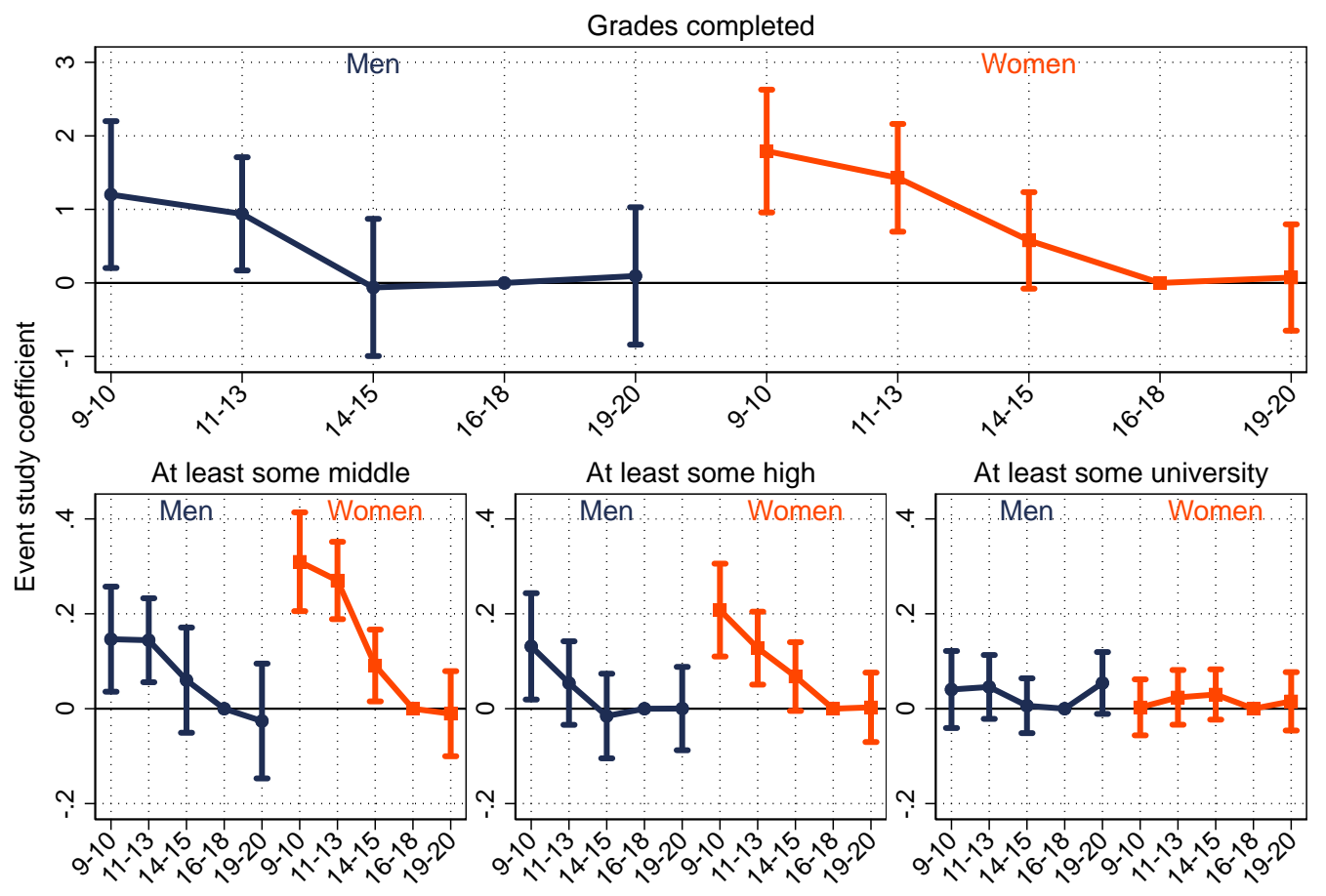

Age in 1997

Note: Coefficients on interactions of cohort indicators with the cumulative enrollment ratio in 1999. The interaction for the cohort aged 16-18 in 1997 is omitted. Capped spikes represent 95\% confidence intervals based on standard errors clustered at the municipality level. All regressions include cohort fixed effects, municipality fixed effects, and interactions of cohort indicators with the cumulative enrollment ratio in 2005. Sample includes individuals in the 2010 Census from high and very high marginality municipalities who were aged 9-13 and 16-20 in 1997. 


\section{Figure 6: Event Studies for Labor Market Outcomes}

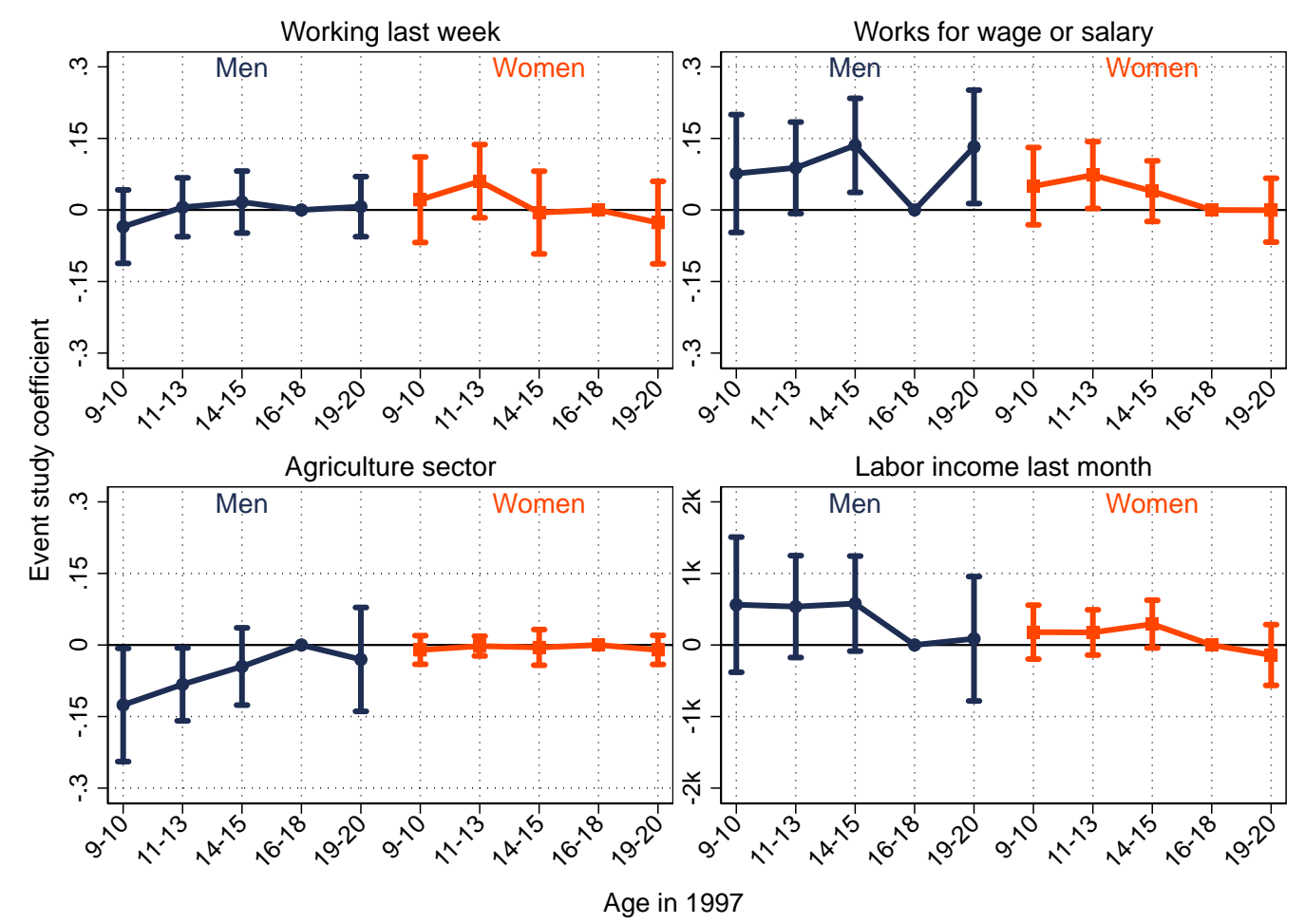

Note: Coefficients on interactions of cohort indicators with the cumulative enrollment ratio in 1999. The interaction for the cohort aged 16-18 in 1997 is omitted. Capped spikes represent $95 \%$ confidence intervals based on standard errors clustered at the municipality level. All regressions include cohort fixed effects, municipality fixed effects, and interactions of cohort indicators with the cumulative enrollment ratio in 2005. Sample includes individuals in the 2010 Census from high and very high marginality municipalities who were aged 9-13 and 16-20 in 1997. 


\section{Figure 7: Program Impacts on the Distribution of Earnings}

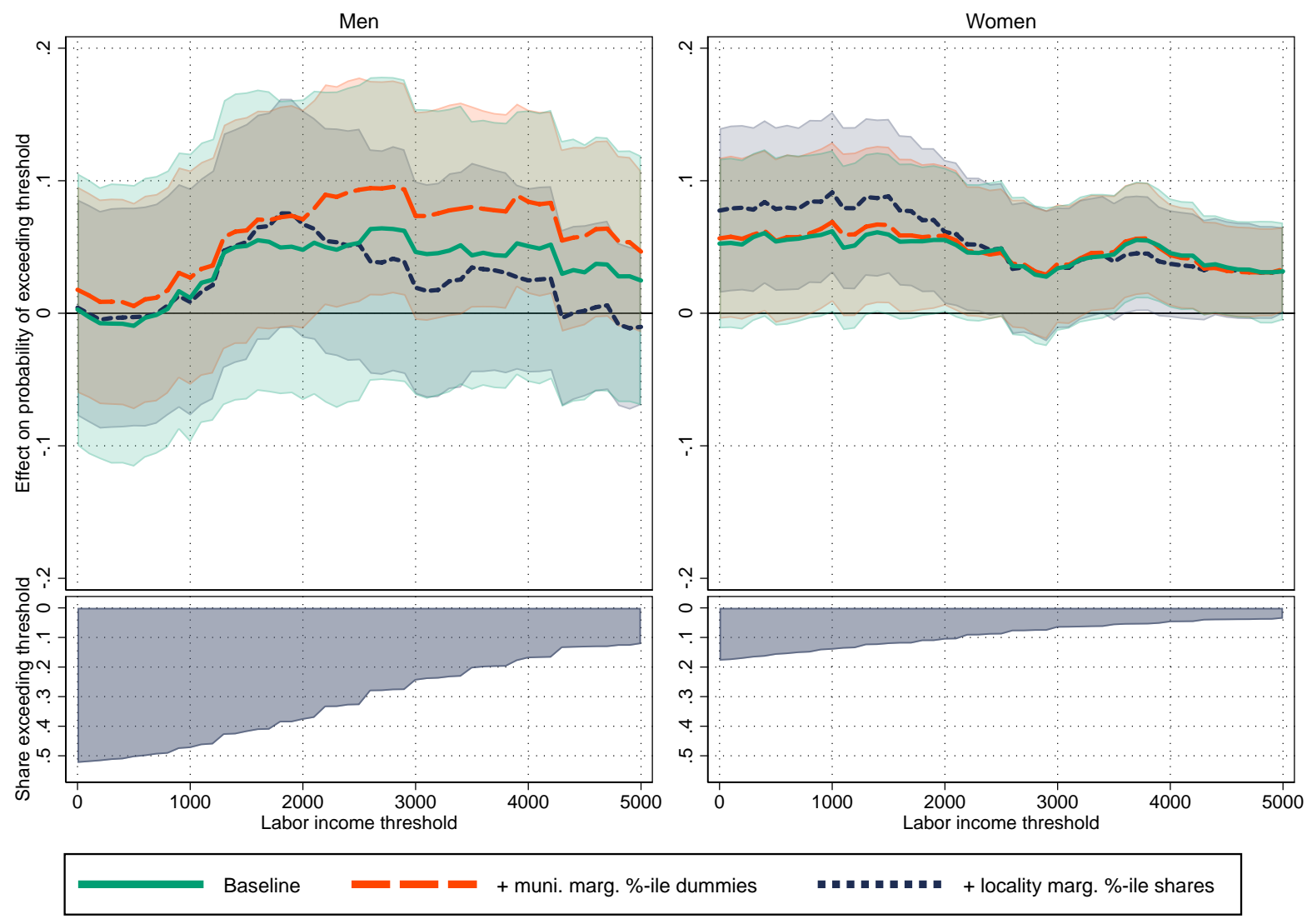

Note: Coefficients on interaction of the post indicator with the cumulative enrollment ratio in 1999.

Dependent variable is an indicator for labor income exceeding the specified threshold, which increases in increments of 100. Income is denominated in 2010 Mexican pesos. Shaded areas represent $95 \%$ confidence intervals based on standard errors clustered at the municipality level. All regressions include cohort and municipality fixed effects, plus the interaction of the post indicator with cumulative enrollment in 2005. Sample includes individuals in the 2010 Census from high and very high marginality municipalities who were aged 9-13 and 16-20 in 1997. 
Figure 8: Event Studies for Household Economic Wellbeing

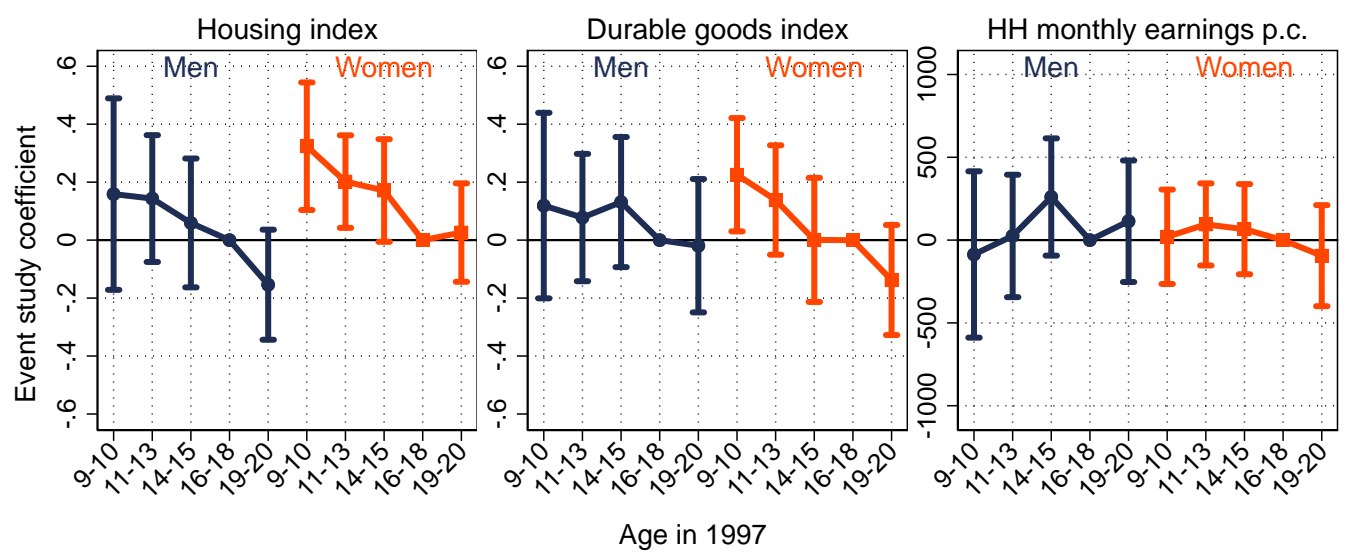

Note: Coefficients on interactions of cohort indicators with the cumulative enrollment ratio in 1999. The interaction for the cohort aged 16-18 in 1997 is omitted. Capped spikes represent 95\% confidence intervals based on standard errors clustered at the municipality level. All regressions include cohort fixed effects, municipality fixed effects, and interactions of cohort indicators with the cumulative enrollment ratio in 2005. Sample includes individuals in the 2010 Census from high and very high marginality municipalities who were aged 9-13 and 16-20 in 1997. 


\section{Figure 9: Event Studies for Migration}

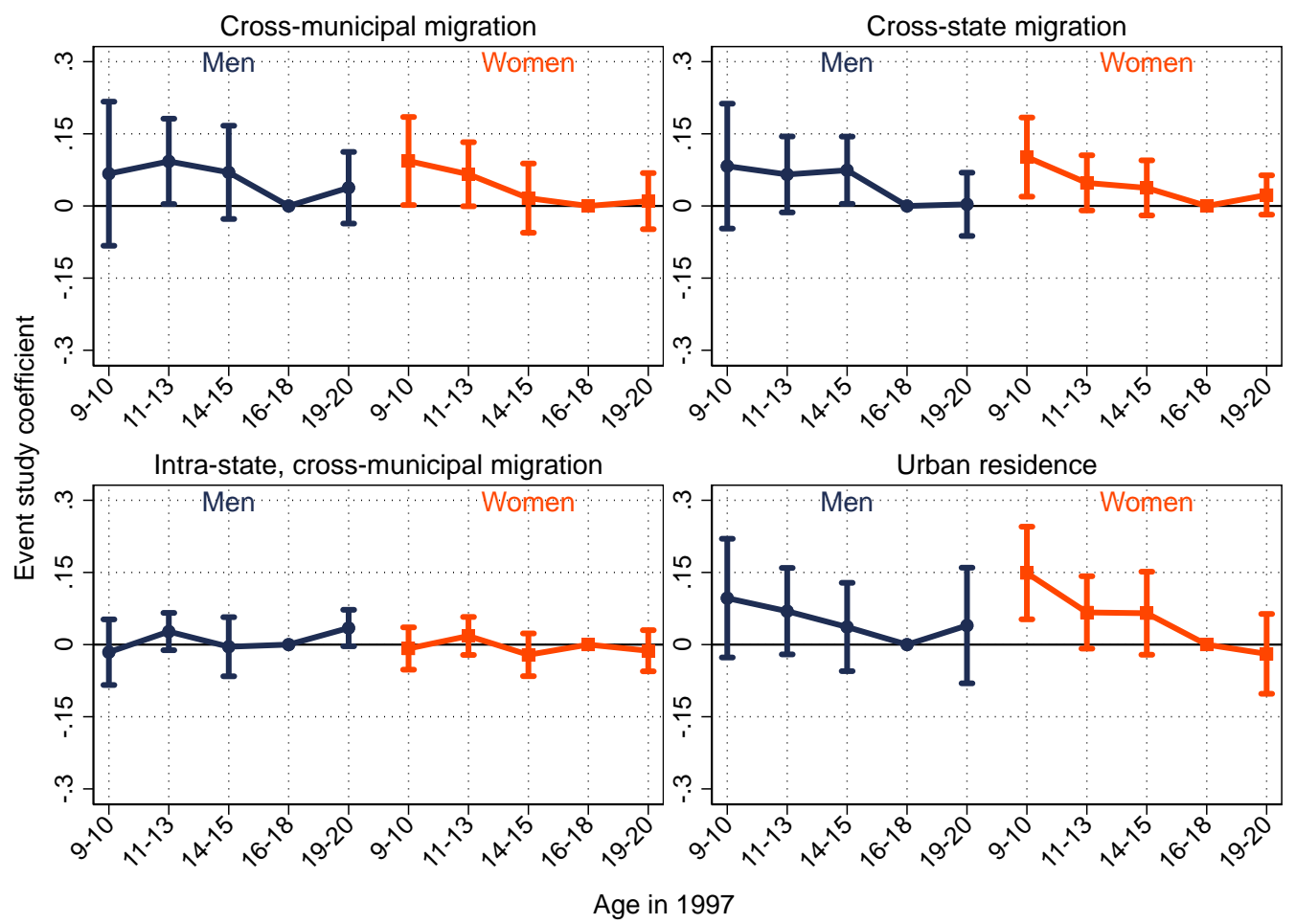

Note: Coefficients on interactions of cohort indicators with the cumulative enrollment ratio in 1999. The interaction for the cohort aged 16-18 in 1997 is omitted. Capped spikes represent $95 \%$ confidence intervals based on standard errors clustered at the municipality level. All regressions include cohort fixed effects, municipality fixed effects, and interactions of cohort indicators with the cumulative enrollment ratio in 2005. Migration is measured between 2005 and 2010. Sample includes individuals in the 2010 Census from high and very high marginality municipalities who were aged 9-13 and 16-20 in 1997. 
Table 1: Summary Statistics for the 2010 Regression Sample

\begin{tabular}{lcc}
\hline & Men & Women \\
\cline { 2 - 3 } A. Program rollout & $(1)$ & $(2)$ \\
Cumulative enrollment ratio, 1999 & $0.34(0.14)$ & $0.34(0.14)$ \\
Cumulative enrollment ratio, 2005 & $0.64(0.22)$ & $0.63(0.22)$ \\
B. Education & & \\
Grades completed & $7.62(4.08)$ & $7.26(4.14)$ \\
At least some middle & $0.53(0.50)$ & $0.48(0.50)$ \\
At least some high & $0.23(0.42)$ & $0.21(0.41)$ \\
At least some university & $0.08(0.28)$ & $0.08(0.27)$ \\
C. Labor market outcomes & & \\
Working & $0.83(0.38)$ & $0.24(0.43)$ \\
Working for a wage & $0.48(0.50)$ & $0.16(0.36)$ \\
Working in agriculture & $0.41(0.49)$ & $0.03(0.17)$ \\
Monthly earnings & $2101(2558)$ & $651(1681)$ \\
D. Household economic wellbeing & & \\
Housing index & $-0.03(1.01)$ & $0.02(0.99)$ \\
Durable goods index & $-0.03(0.99)$ & $0.02(1.00)$ \\
Household monthly earnings per capita & $902(1241)$ & $768(1128)$ \\
E. Migration & & \\
Cross-municipal migration & $0.06(0.24)$ & $0.06(0.24)$ \\
Cross-state migration & $0.04(0.19)$ & $0.04(0.18)$ \\
Cross-municipal, intra-state migration & $0.02(0.14)$ & $0.03(0.16)$ \\
Urban residence & $0.35(0.48)$ & $0.35(0.48)$ \\
Number of observations & 301,140 & 358,339 \\
Number of municipalities & 1143 & 1143 \\
\hline Note: Parentheses contan standard & & \\
\hline
\end{tabular}

Note: Parentheses contain standard errors. The cumulative enrollment ratio in year $t$ is the number of households enrolled in Progresa up to and including $t$ divided by the estimated number of households in 1997. All labor market outcomes are unconditional on labor force participation. Earnings and earnings per capita are denominated in 2010 Mexican pesos (1 MEX $\$=0.13$ US $\$$ PPP in 2010 [Penn World Table v9.1]). The housing index is the standardized first principle component of indicators for a dirt floor, a modern roof, sewage, a flush toilet, piped water, and electricity. The durable goods index is the standardized first principle component of indicators for a car, a mobile phone, a computer, a washing machine, a refrigerator, a television, and a hot water heater. Migration is measured between 2005 and 2010. Sample includes individuals from high and very high marginality municipalities who were aged 913 and 16-20 in 1997. 
Table 2: Program Impacts on Educational Attainment

\begin{tabular}{|c|c|c|c|c|c|c|c|c|}
\hline & \multicolumn{4}{|c|}{ Men } & \multicolumn{4}{|c|}{ Women } \\
\hline & \multicolumn{3}{|c|}{2010} & \multirow{2}{*}{$\begin{array}{c}1990 \\
(4)\end{array}$} & \multicolumn{3}{|c|}{2010} & \multirow{2}{*}{$\frac{1990}{(8)}$} \\
\hline & (1) & $(2)$ & (3) & & (5) & $(6)$ & (7) & \\
\hline \multicolumn{9}{|l|}{ A. Grades completed } \\
\hline $\begin{array}{l}\text { Enrollment ratio, } 1999 \\
\times \text { post cohort }\end{array}$ & $\begin{array}{c}1.026 \\
{[0.360]^{* * *}}\end{array}$ & $\begin{array}{c}0.866 \\
{[0.327]^{* * *}}\end{array}$ & $\begin{array}{c}0.596 \\
{[0.315]^{*}}\end{array}$ & $\begin{array}{c}0.671 \\
{[0.813]}\end{array}$ & $\begin{array}{c}1.570 \\
{[0.307]^{* * *}}\end{array}$ & $\begin{array}{c}1.374 \\
{[0.311]^{* * *}}\end{array}$ & $\begin{array}{c}1.032 \\
{[0.309]^{* * *}}\end{array}$ & $\begin{array}{c}0.528 \\
{[0.629]}\end{array}$ \\
\hline$N$ & 299,237 & 299,237 & 299,237 & 84,489 & 355,986 & 355,986 & 355,986 & 90,433 \\
\hline \multicolumn{9}{|l|}{ B. At least some middle } \\
\hline $\begin{array}{l}\text { Enrollment ratio, } 1999 \\
\times \text { post cohort }\end{array}$ & $\begin{array}{c}0.156 \\
{[0.050]^{* * *}}\end{array}$ & $\begin{array}{c}0.163 \\
{[0.043]^{* * *}}\end{array}$ & $\begin{array}{c}0.130 \\
{[0.043]^{* * *}}\end{array}$ & $\begin{array}{c}0.041 \\
{[0.042]}\end{array}$ & $\begin{array}{c}0.293 \\
{[0.038]^{* * *}}\end{array}$ & $\begin{array}{c}0.302 \\
{[0.039]^{* * *}}\end{array}$ & {$[0.225$} & $\begin{array}{c}0.018 \\
{[0.032]}\end{array}$ \\
\hline$N$ & 299,906 & 299,906 & 299,906 & 84,489 & 356,801 & 356,801 & 356,801 & 90,433 \\
\hline \multicolumn{9}{|l|}{ C. At least some high } \\
\hline $\begin{array}{l}\text { Enrollment ratio, } 1999 \\
\times \text { post cohort }\end{array}$ & $\begin{array}{c}0.088 \\
{[0.039]^{* *}}\end{array}$ & $\begin{array}{c}0.088 \\
{[0.037]^{* *}}\end{array}$ & $\begin{array}{c}0.034 \\
{[0.038]}\end{array}$ & $\begin{array}{c}0.008 \\
{[0.026]}\end{array}$ & $\begin{array}{c}0.161 \\
{[0.036]^{* * *}}\end{array}$ & $\begin{array}{c}0.170 \\
{[0.032]^{* * *}}\end{array}$ & $\begin{array}{c}0.169 \\
{[0.032]^{* * *}}\end{array}$ & $\begin{array}{c}0.008 \\
{[0.021]}\end{array}$ \\
\hline$N$ & 299,906 & 299,906 & 299,906 & 84,489 & 356,801 & 356,801 & 356,801 & 90,433 \\
\hline \multicolumn{9}{|l|}{ D. At least some university } \\
\hline $\begin{array}{l}\text { Enrollment ratio, } 1999 \\
\times \text { post cohort }\end{array}$ & $\begin{array}{c}0.023 \\
{[0.028]}\end{array}$ & $\begin{array}{c}0.029 \\
{[0.023]}\end{array}$ & $\begin{array}{c}0.016 \\
{[0.024]}\end{array}$ & $\begin{array}{c}0.007 \\
{[0.021]}\end{array}$ & $\begin{array}{c}0.009 \\
{[0.021]}\end{array}$ & $\begin{array}{c}0.016 \\
{[0.020]}\end{array}$ & $\begin{array}{c}0.017 \\
{[0.020]}\end{array}$ & $\begin{array}{l}-0.012 \\
{[0.015]}\end{array}$ \\
\hline$N$ & 299,906 & 299,906 & 299,906 & 84,489 & 356,801 & 356,801 & 356,801 & 90,433 \\
\hline $\begin{array}{l}\text { Municipality FE, cohort FE } \\
\text { Cohort dummies } \times\end{array}$ & $\mathrm{X}$ & $\mathrm{X}$ & $X$ & $X$ & $X$ & $X$ & $X$ & $X$ \\
\hline $\begin{array}{l}\text { Muni. marg. \%-ile dummies } \\
\text { Locality marg. \%-ile shares }\end{array}$ & & $X$ & $\begin{array}{l}X \\
X\end{array}$ & & & $x$ & $\begin{array}{l}X \\
X\end{array}$ & \\
\hline
\end{tabular}

Note: Brackets contain standard errors clustered at the municipality level. All regressions additionally control for the interaction of the post indicator with the cumulative enrollment ratio in 2005. Samples include individuals from high and very high marginality municipalities who were aged 9-13 and 16-20 thirteen years before the census. ${ }^{*} p<0.1,{ }^{* *} p<0.05,{ }^{* * *} p<0.01$. 
Table 3: Program Impacts on Labor Market Outcomes

\begin{tabular}{|c|c|c|c|c|c|c|c|c|}
\hline & \multicolumn{4}{|c|}{ Men } & \multicolumn{4}{|c|}{ Women } \\
\hline & \multicolumn{3}{|c|}{2010} & \multirow{2}{*}{$\begin{array}{c}1990 \\
(4)\end{array}$} & \multicolumn{3}{|c|}{2010} & \multirow{2}{*}{$\begin{array}{c}1990 \\
(8)\end{array}$} \\
\hline & (1) & $(2)$ & (3) & & (5) & $(6)$ & (7) & \\
\hline \multicolumn{9}{|l|}{ A. Working } \\
\hline \multirow{2}{*}{$\begin{array}{l}\text { Enrollment ratio, } 1999 \\
\times \text { post cohort }\end{array}$} & -0.015 & -0.008 & 0.001 & 0.016 & 0.053 & 0.062 & 0.093 & 0.007 \\
\hline & {$[0.030]$} & {$[0.028]$} & {$[0.030]$} & [0.033] & {$[0.032]^{*}$} & {$[0.031]^{* *}$} & {$[0.031]^{* * *}$} & [0.026] \\
\hline$N$ & 299,515 & 299,515 & 299,515 & 83,938 & 357,018 & 357,018 & 357,018 & 89,583 \\
\hline \multicolumn{9}{|l|}{ B. Working for a wage } \\
\hline \multirow{2}{*}{$\begin{array}{l}\text { Enrollment ratio, } 1999 \\
\times \text { post cohort }\end{array}$} & 0.032 & 0.072 & 0.059 & 0.043 & 0.063 & 0.077 & 0.073 & -0.011 \\
\hline & {$[0.040]$} & {$[0.039]^{*}$} & {$[0.042]$} & [0.047] & {$[0.029]^{* *}$} & {$[0.027]^{* * *}$} & {$[0.027]^{* * *}$} & [0.018] \\
\hline$N$ & 293,165 & 293,165 & 293,165 & 79,896 & 354,440 & 354,440 & 354,440 & 88,522 \\
\hline \multicolumn{9}{|l|}{ C. Working in agriculture } \\
\hline \multirow{2}{*}{$\begin{array}{l}\text { Enrollment ratio, } 1999 \\
\times \text { post cohort }\end{array}$} & -0.090 & -0.107 & -0.050 & 0.060 & -0.002 & 0.002 & 0.009 & 0.014 \\
\hline & {$[0.046]^{*}$} & {$[0.035]^{* * *}$} & [0.035] & [0.046] & {$[0.008]$} & {$[0.008]$} & [0.009] & [0.011] \\
\hline$N$ & 297,315 & 297,315 & 297,315 & 82,402 & 355,898 & 355,898 & 355,898 & 88,518 \\
\hline \multicolumn{9}{|l|}{ D. Monthly earnings } \\
\hline \multirow{2}{*}{$\begin{array}{l}\text { Enrollment ratio, } 1999 \\
\times \text { post cohort }\end{array}$} & 494 & 729 & 268 & 599 & 236 & 268 & 255 & -11 \\
\hline & {$[383]$} & {$[256]^{* * *}$} & {$[261]$} & {$[352]^{*}$} & {$[137]^{*}$} & {$[135]^{* *}$} & {$[139]^{*}$} & [142] \\
\hline$N$ & 288,431 & 288,431 & 288,431 & 81,053 & 352,835 & 352,835 & 354,156 & 89,657 \\
\hline Municipality FE, cohort FE & $x$ & $x$ & $x$ & $x$ & $x$ & $x$ & $x$ & $x$ \\
\hline \multicolumn{9}{|l|}{ Cohort dummies $\times$} \\
\hline Muni. marg. \%-ile dummies & & $\mathrm{X}$ & $x$ & & & $x$ & $X$ & \\
\hline Locality marg. \%-ile shares & & & $X$ & & & & $X$ & \\
\hline
\end{tabular}

Note: Brackets contain standard errors clustered at the municipality level. All regressions additionally control for the interaction of the post indicator with the cumulative enrollment ratio in 2005. All labor market outcomes are unconditional on labor force participation. Earnings are denominated in 2010 Mexican pesos (1 MEX\$ = 0.13 US\$ PPP in 2010). Samples include individuals from high and very high marginality municipalities who were aged $9-13$ and $16-20$ thirteen years before the census. ${ }^{*} p<0.1,{ }^{* *} p<$ $0.05,{ }^{* * *} p<0.01$. 
Table 4: Program Impacts on Household Economic Wellbeing

\begin{tabular}{|c|c|c|c|c|c|c|c|c|}
\hline & \multicolumn{4}{|c|}{ Men } & \multicolumn{4}{|c|}{ Women } \\
\hline & \multicolumn{3}{|c|}{2010} & \multirow{2}{*}{$\frac{1990}{(4)}$} & \multicolumn{3}{|c|}{2010} & \multirow{2}{*}{$\begin{array}{c}1990 \\
(8)\end{array}$} \\
\hline & (1) & (2) & (3) & & (5) & (6) & (7) & \\
\hline \multicolumn{9}{|l|}{ A. Housing index } \\
\hline $\begin{array}{l}\text { Enrollment ratio, } 1999 \\
\times \text { post cohort }\end{array}$ & $\begin{array}{c}0.209 \\
{[0.114]^{*}}\end{array}$ & $\begin{array}{c}0.239 \\
{[0.099]^{* *}}\end{array}$ & $\begin{array}{c}0.199 \\
{[0.103]^{*}}\end{array}$ & $\begin{array}{l}-0.019 \\
{[0.087]}\end{array}$ & $\begin{array}{c}0.243 \\
{[0.065]^{* * *}}\end{array}$ & $\begin{array}{c}0.253 \\
*[0.070]^{* * *}\end{array}$ & $\begin{array}{c}0.187 \\
{[0.072]^{* * *}}\end{array}$ & $\begin{array}{c}0.019 \\
{[0.082]}\end{array}$ \\
\hline$N$ & 294,969 & 294,969 & 294,969 & 80,947 & 351,077 & 351,077 & 351,077 & 86,673 \\
\hline \multicolumn{9}{|l|}{ B. Durable goods index } \\
\hline $\begin{array}{l}\text { Enrollment ratio, } 1999 \\
\times \text { post cohort }\end{array}$ & $\begin{array}{c}0.105 \\
{[0.110]}\end{array}$ & $\begin{array}{c}0.098 \\
{[0.094]}\end{array}$ & $\begin{array}{c}0.050 \\
{[0.097]}\end{array}$ & - & $\begin{array}{c}0.229 \\
{[0.073]^{* * *}}\end{array}$ & $\begin{array}{c}0.194 \\
{[0.062]^{* * *}}\end{array}$ & $\begin{array}{c}0.146 \\
{[0.062]^{* *}}\end{array}$ & - \\
\hline$N$ & 295,927 & 295,927 & 295,927 & & 352,337 & 352,337 & 352,337 & \\
\hline \multicolumn{9}{|c|}{ C. HH monthly earnings p.c. } \\
\hline $\begin{array}{l}\text { Enrollment ratio, } 1999 \\
\times \text { post cohort }\end{array}$ & $\begin{array}{c}-75 \\
{[177]}\end{array}$ & $\begin{array}{c}74 \\
{[138]}\end{array}$ & $\begin{array}{c}34 \\
{[148]}\end{array}$ & $\begin{array}{c}-26 \\
{[178]}\end{array}$ & $\begin{array}{c}97 \\
{[92]}\end{array}$ & $\begin{array}{c}90 \\
{[89]}\end{array}$ & $\begin{array}{c}71 \\
{[94]}\end{array}$ & $\begin{array}{c}28 \\
{[123]}\end{array}$ \\
\hline$N$ & 292,360 & 292,360 & 292,360 & 84,405 & 356,100 & 356,100 & 356,100 & 90,334 \\
\hline $\begin{array}{l}\text { Municipality FE, cohort FE } \\
\text { Cohort dummies } \times\end{array}$ & $X$ & $X$ & $\mathrm{X}$ & $\mathrm{X}$ & $X$ & $X$ & $X$ & $X$ \\
\hline Muni. marg. \%-ile dummies & & $X$ & $\begin{array}{l}x \\
x\end{array}$ & & & $X$ & $\begin{array}{l}x \\
x\end{array}$ & \\
\hline
\end{tabular}

Note: Brackets contain standard errors clustered at the municipality level. All regressions additionally control for the interaction of the post indicator with the cumulative enrollment ratio in 2005. Earnings and earnings per capita are denominated in 2010 Mexican pesos (1 MEX $\$=0.13$ US\$ PPP in 2010). The 1990 census did not collect data on durable goods ownership. Samples include individuals from high and very high marginality municipalities who were aged 9-13 and 16-20 thirteen years before the census. ${ }^{*} p<0.1$, ${ }^{* *} p<0.05,{ }^{* * *} p<0.01$. 
Table 5: Program Impacts on Migration

\begin{tabular}{|c|c|c|c|c|c|c|c|c|}
\hline & \multicolumn{4}{|c|}{ Men } & \multicolumn{4}{|c|}{ Women } \\
\hline & \multicolumn{3}{|c|}{2010} & \multirow{2}{*}{$\begin{array}{l}1990 \\
(4) \\
\end{array}$} & \multicolumn{3}{|c|}{2010} & \multirow{2}{*}{$\frac{1990}{(8)}$} \\
\hline & (1) & $(2)$ & (3) & & (5) & $(6)$ & (7) & \\
\hline \multicolumn{9}{|l|}{ A. Cross-muni migration } \\
\hline $\begin{array}{l}\text { Enrollment ratio, } 1999 \\
\times \text { post cohort }\end{array}$ & 0.067 & 0.104 & 0.072 & - & 0.073 & 0.076 & 0.062 & - \\
\hline${ }_{N}^{\times \text {post cohort }}$ & $\begin{array}{l}{[0.052]} \\
301,140\end{array}$ & $\begin{array}{c}{[0.039]^{* * *}} \\
301,140\end{array}$ & $\begin{array}{l}{[0.041]^{*}} \\
301,140\end{array}$ & & $\begin{array}{c}{[0.031]^{* *}} \\
358,339\end{array}$ & $\begin{array}{c}{[0.029]^{* * *}} \\
358,339\end{array}$ & $\begin{array}{c}{[0.029]^{* *}} \\
358,339\end{array}$ & \\
\hline \multicolumn{9}{|l|}{ B. Cross-state migration } \\
\hline $\begin{array}{l}\text { Enrollment ratio, } 1999 \\
\times \text { post cohort }\end{array}$ & $\begin{array}{c}0.073 \\
{[0.046]}\end{array}$ & $\begin{array}{c}0.101 \\
{[0.035]^{* * *}}\end{array}$ & $\begin{array}{c}0.074 \\
{[0.036]^{* *}}\end{array}$ & $\begin{array}{c}0.014 \\
{[0.014]}\end{array}$ & $\begin{array}{c}0.062 \\
{[0.027]^{* *}}\end{array}$ & $\begin{array}{c}0.068 \\
{[0.026]^{* * *}}\end{array}$ & $\begin{array}{c}0.063 \\
{[0.026]^{* *}}\end{array}$ & $\begin{array}{l}-0.005 \\
{[0.013]}\end{array}$ \\
\hline$N$ & 301,140 & 301,140 & 301,140 & 84,062 & 358,339 & 358,339 & 358,339 & 89,977 \\
\hline \multicolumn{9}{|l|}{ C. Intra-state migration } \\
\hline $\begin{array}{l}\text { Enrollment ratio, } 1999 \\
\times \text { post cohort }\end{array}$ & $\begin{array}{l}-0.006 \\
{[0.022]}\end{array}$ & $\begin{array}{c}0.003 \\
{[0.018]}\end{array}$ & $\begin{array}{c}-0.002 \\
{[0.018]}\end{array}$ & - & $\begin{array}{c}0.012 \\
{[0.016]}\end{array}$ & $\begin{array}{c}0.008 \\
{[0.016]}\end{array}$ & $\begin{array}{l}-0.001 \\
{[0.016]}\end{array}$ & - \\
\hline$N$ & 301,140 & 301,140 & 301,140 & & 358,339 & 358,339 & 358,339 & \\
\hline \multicolumn{9}{|l|}{ D. Urban residence } \\
\hline $\begin{array}{l}\text { Enrollment ratio, } 1999 \\
\times \text { post cohort }\end{array}$ & $\begin{array}{c}0.066 \\
{[0.050]}\end{array}$ & $\begin{array}{c}0.081 \\
{[0.043]^{*}}\end{array}$ & $\begin{array}{c}0.077 \\
{[0.043]^{*}}\end{array}$ & $\begin{array}{c}-0.078 \\
{[0.034]^{* *}}\end{array}$ & $\begin{array}{c}0.110 \\
{[0.034]^{* * *}}\end{array}$ & $\begin{array}{c}0.086 \\
{[0.032]^{* * *}}\end{array}$ & $\begin{array}{c}0.044 \\
{[0.033]}\end{array}$ & $\begin{array}{c}0.041 \\
{[0.033]}\end{array}$ \\
\hline$N$ & 301,140 & 301,140 & 301,140 & 84,489 & 358,339 & 358,339 & 358,339 & 90,433 \\
\hline $\begin{array}{l}\text { Municipality FE, cohort FE } \\
\text { Cohort dummies } \times\end{array}$ & $x$ & $x$ & $x$ & $X$ & $X$ & $x$ & $x$ & $x$ \\
\hline Muni. marg. \%-ile dummies & & $x$ & $\mathrm{X}$ & & & $X$ & $x$ & \\
\hline Locality marg. \%-ile shares & & & $X$ & & & & $X$ & \\
\hline
\end{tabular}

Note: Brackets contain standard errors clustered at the municipality level. All regressions additionally control for the interaction of the post indicator with the cumulative enrollment ratio in 2005. Migration is measured over the five years prior to the census. The 1990 census did not collect data on cross-municipal migration. Samples include individuals from high and very high marginality municipalities who were aged 9-13 and 16-20 thirteen years before the census. ${ }^{*} p<0.1,{ }^{* *} p<0.05,{ }^{* * *} p<0.01$. 
FOR ONLINE APPENDIX 
Figure A1: Maps of the Municipality Enrollment Ratio by Implementation Phase

A. 1997-1999

$$
<.1=.1-.25=.25-.5=.5-.75=>.75
$$

B. 2000-2005

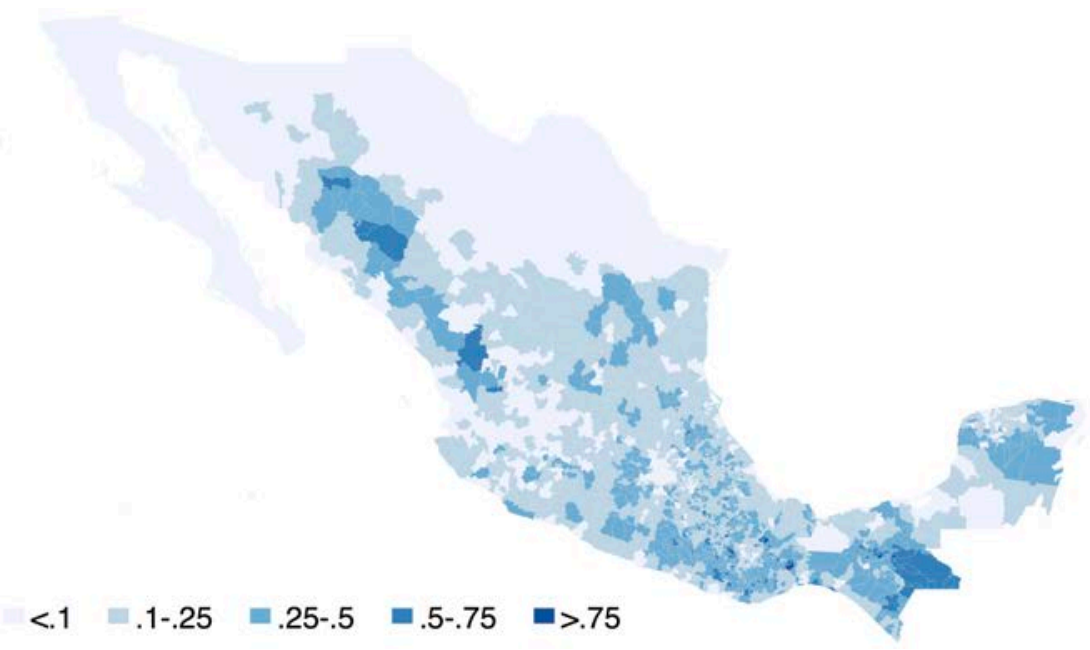

Note: The municipality enrollment ratio is the count of new households enrolled divided by the estimated number of households 1997. 
Figure A2: Age Heaping, 2010 Census

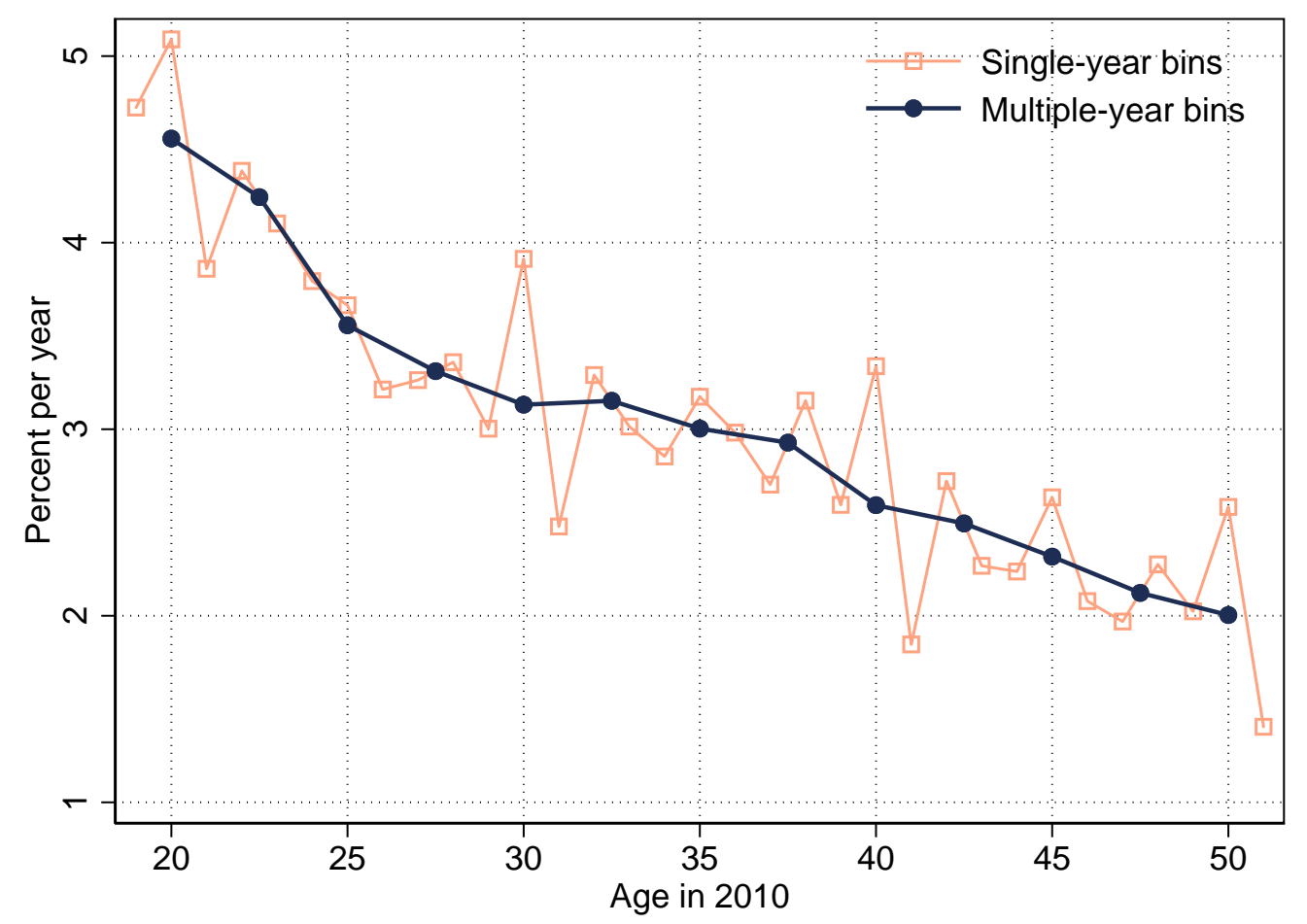

Note: Sample includes respondents who lived in sample municipalities in 2005 and reported ages between 19 and 51. Multiple-year bins centered on multiples of 5 are 3 years wide (19-21, 24-26, 29-31, etc.); those in between are 2 years wide (22-23, 27-28, 32-33, etc.). 
Figure A3: Differential Age Heaping by Educational Attainment, 2010 Census

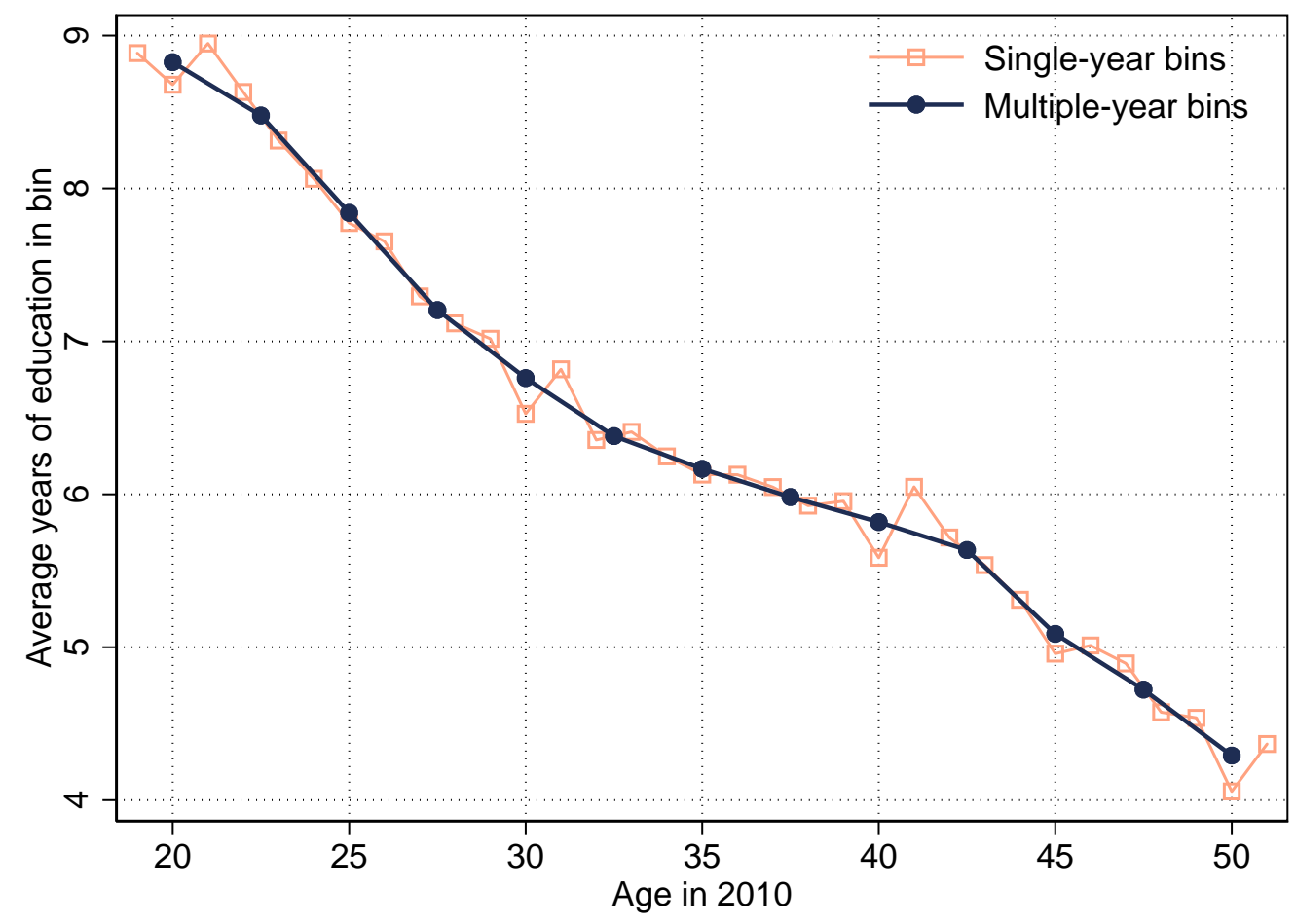

Note: Sample includes respondents who lived in sample municipalities in 2005 and reported ages between 19 and 51. Multiple-year bins centered on multiples of 5 are 3 years wide (19-21, 24-26, 29-31, etc.); those in between are 2 years wide (22-23, 27-28, 32-33, etc.). 
Figure A4: School Enrollment by Age, 2000 Census

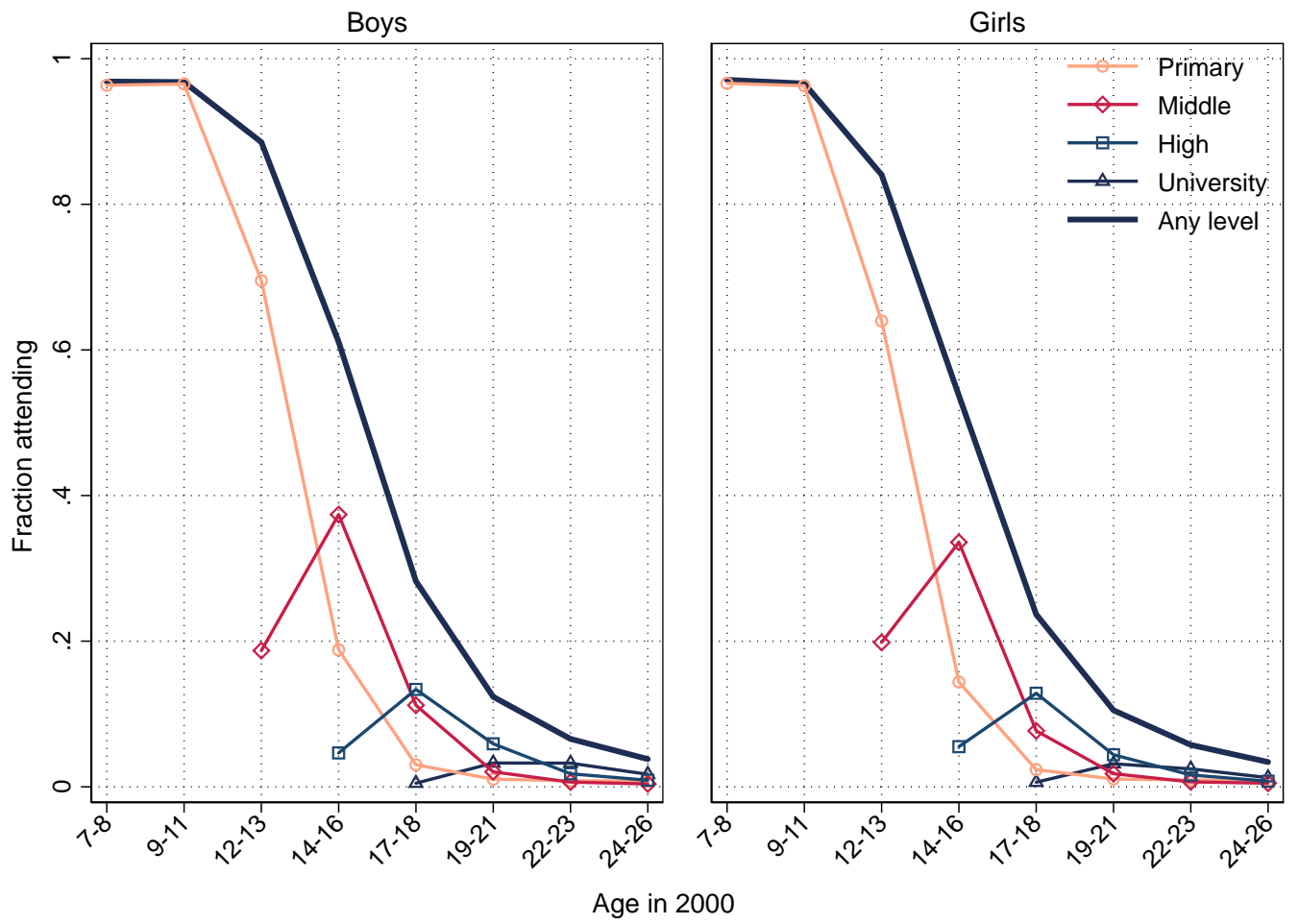

Note: School enrollment in sample municipalities in the 2000 Census. Cash transfer conditionality was limited to primary and middle school in the first program wave (1997-99). 
Figure A5: Effect of Early Program Exposure on Municipal Cohort Size and Composition

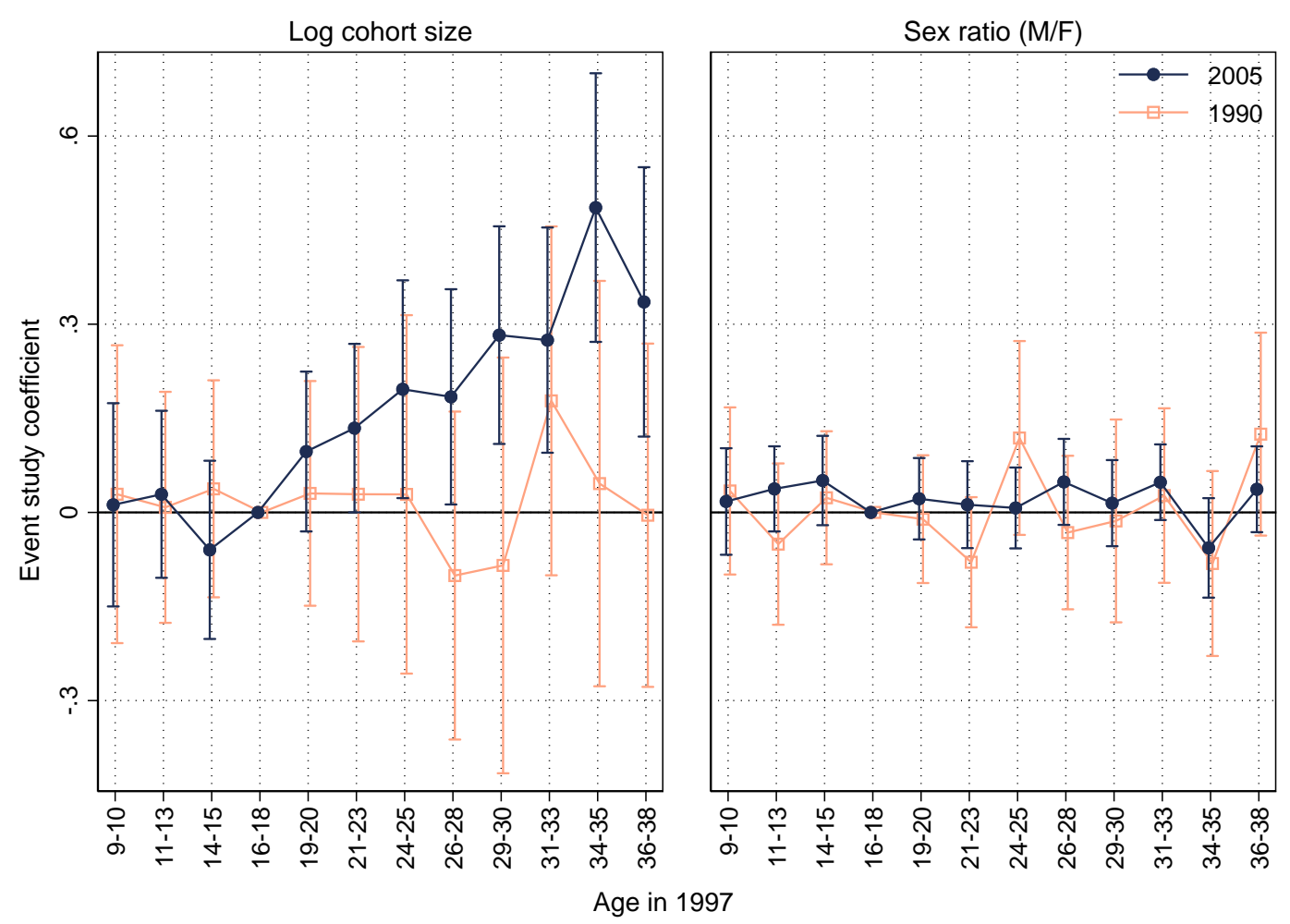

Note: Coefficients on interactions of cohort indicators with the cumulative enrollment ratio in 1999.

Capped spikes represent $95 \%$ confidence intervals based on standard errors clustered at the state level. Regressions include cohort fixed effects, municipality fixed effects, and interactions of cohort indicators with the cumulative enrollment ratio in 2005. For consistency with our main event study graphs, the interaction for the cohort aged 16-18 in 1997 is omitted. 2005 results are based on the 2010 census; 1990 results are based on the 1990 census. 
Figure A6: Effects on Educational Attainment by Grade, 2010 Census

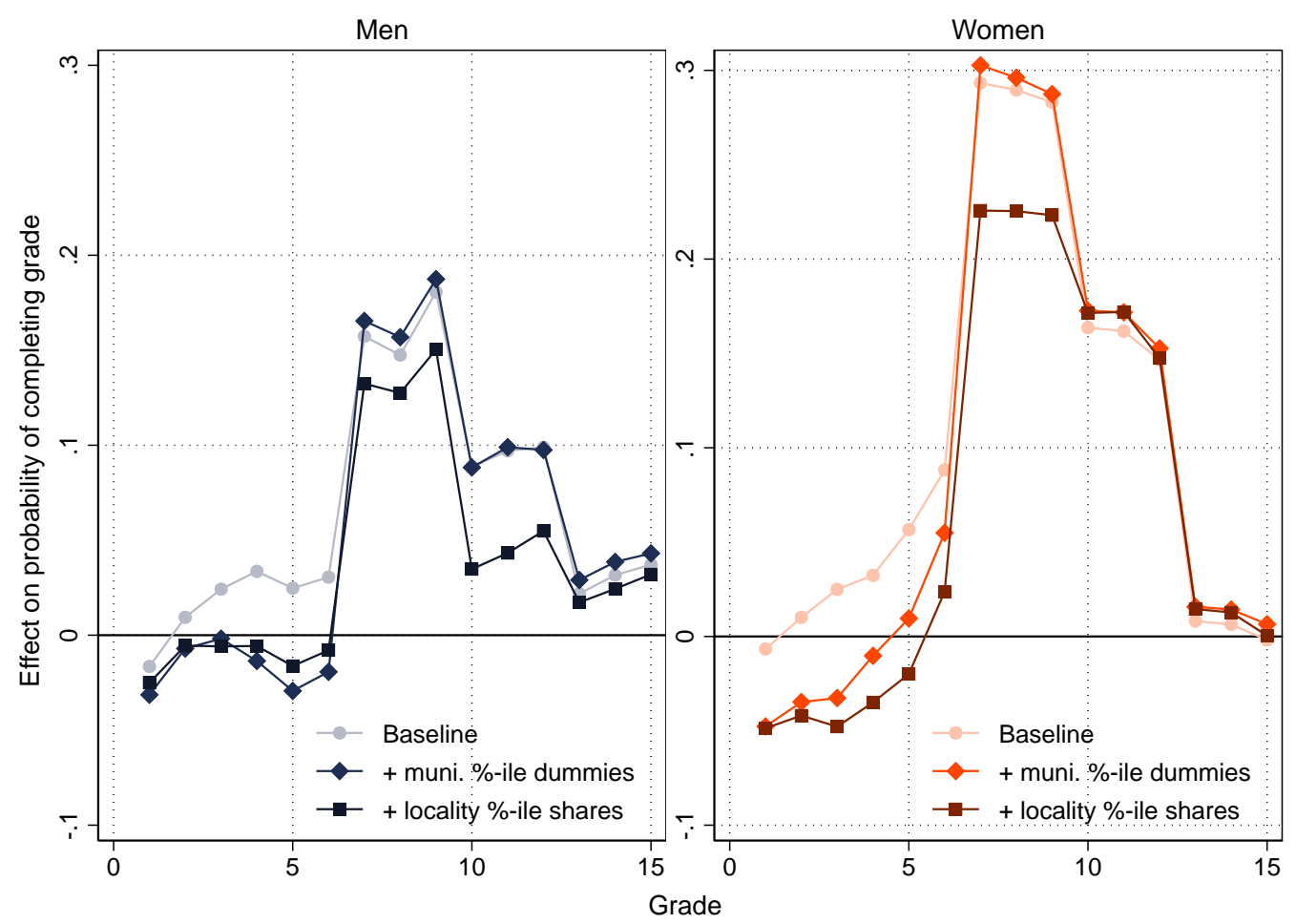

Note: Coefficients on the interaction of the post-cohort indicator with the cumulative enrollment ratio in 1999. Each point is from a different regression in which the dependent variable is an indicator for completing at least $x$ years of schooling. All regressions include cohort fixed effects, municipality fixed effects, and the interaction of the post-cohort indicator with the cumulative enrollment ratio in 2005.

Sample includes individuals in the 2010 Census from high and very high marginality municipalities who were aged 9-13 and 16-20 in 1997. 
Figure A7: Falsification Test for Income Distribution Impacts, 1990 Census
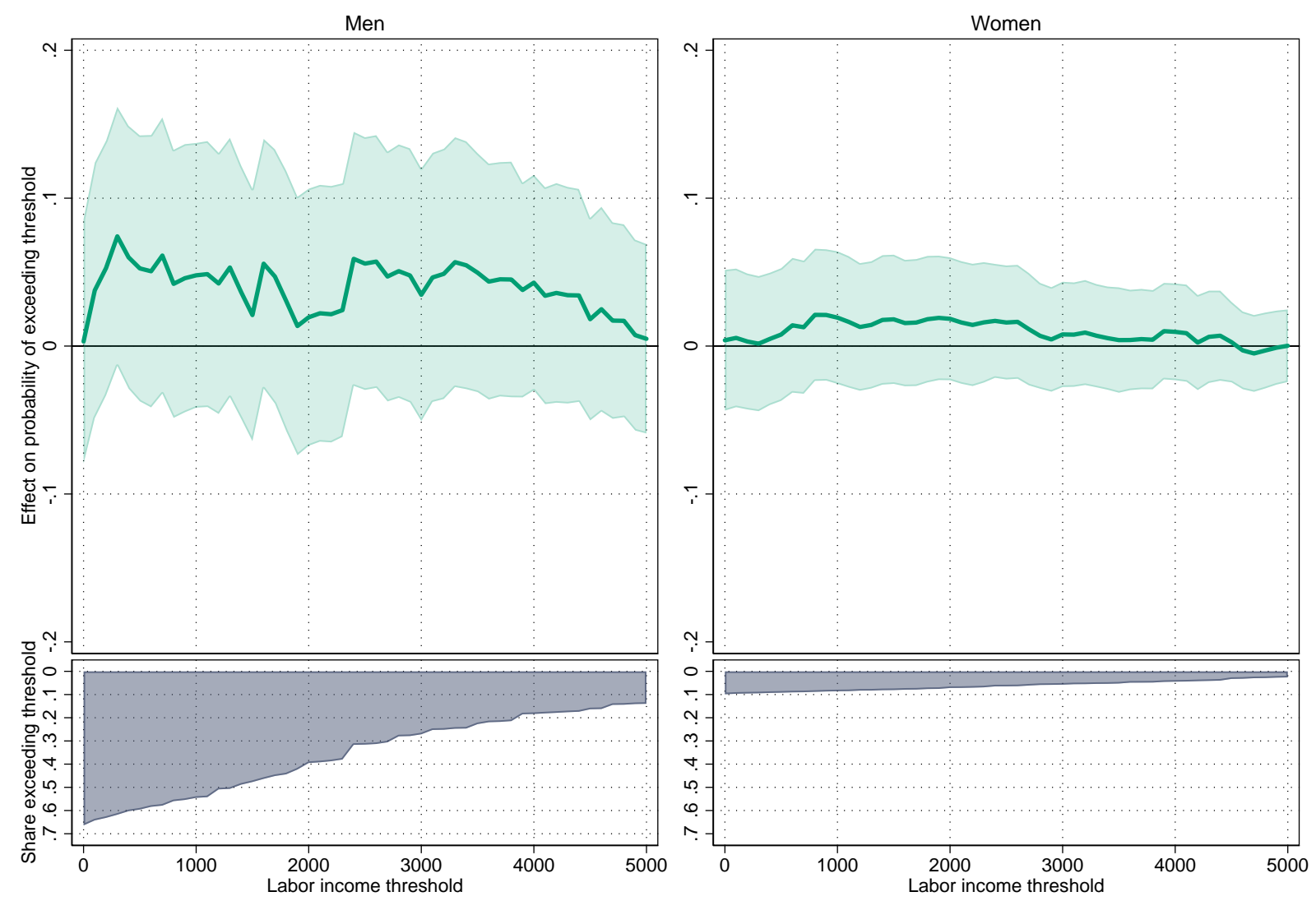

Note: Coefficients on interaction of the post indicator with the cumulative enrollment ratio in 1999. Dependent variable is an indicator for labor income exceeding the specified threshold, which increases in increments of 100. Income is denominated in 2010 Mexican pesos. Shaded areas represent $95 \%$ confidence intervals based on standard errors clustered at the municipality level. Regressions include cohort and municipality fixed effects, plus the interaction of the post indicator with cumulative enrollment in 2005. 
Figure A8: Trends in Secondary School Attainment by State of Birth, 2010 Census

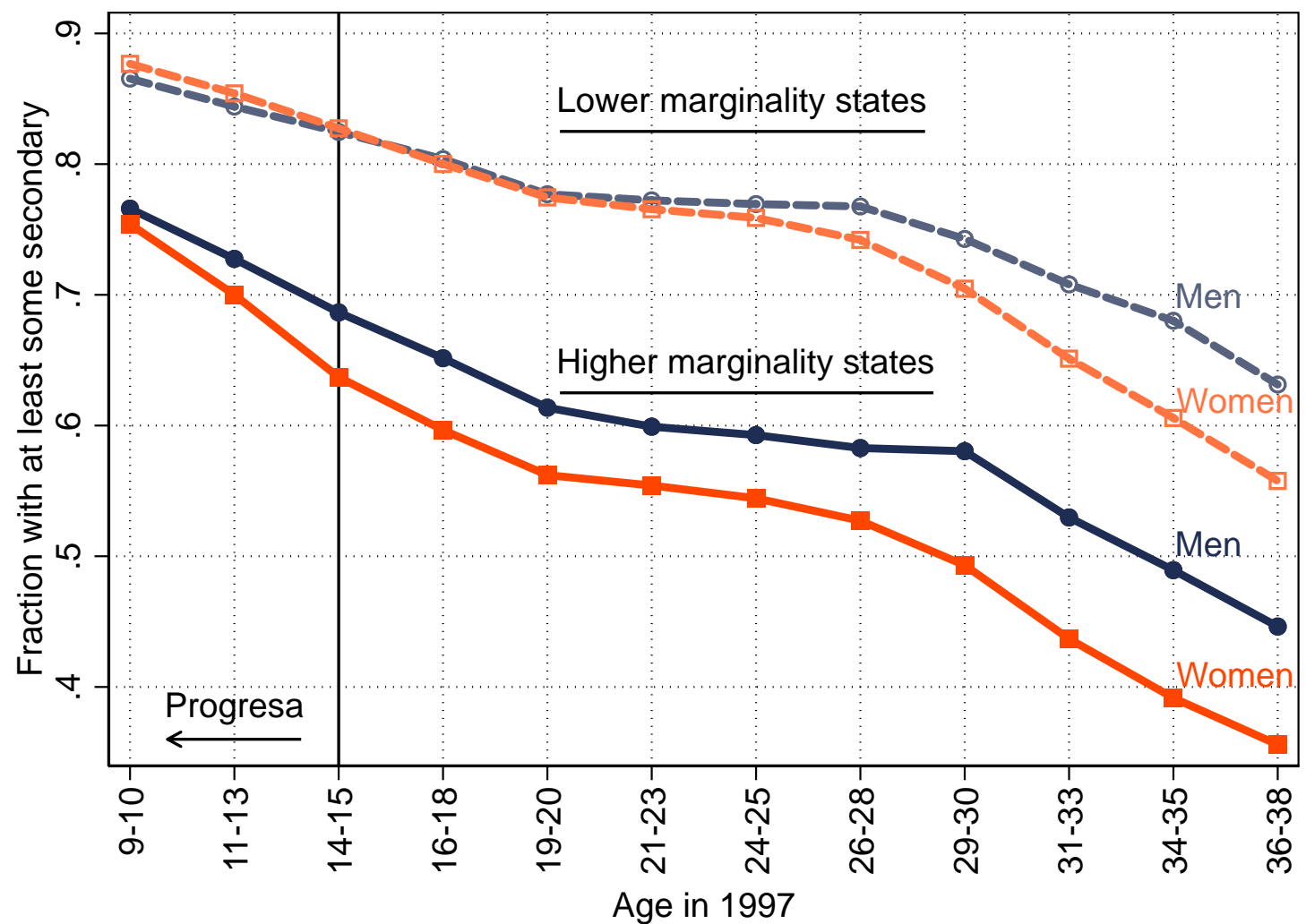

Note: We use state of birth instead of the 5-year lag of municipality to allow the inclusion of older cohorts without introducing concerns about migration. Because marginality classifications are not available for the period in which the oldest cohorts were children, we use the marginality classification from 2010. 
Table A1: Monthly Amount of Schooling Grants, 1997 and 2003

\begin{tabular}{|c|c|c|c|c|}
\hline & \multicolumn{2}{|c|}{$2^{\text {nd }}$ semester 1997} & \multicolumn{2}{|c|}{$2^{\text {nd }}$ semester 2003} \\
\hline & Boys & Girls & Boys & Girls \\
\hline \multicolumn{5}{|l|}{ Primary school } \\
\hline $3^{\text {rd }}$ year & 60 & 60 & 105 & 105 \\
\hline $4^{\text {th }}$ year & 70 & 70 & 120 & 120 \\
\hline $5^{\text {th }}$ year & 90 & 90 & 155 & 155 \\
\hline $6^{\text {th }}$ year & 120 & 120 & 210 & 210 \\
\hline \multicolumn{5}{|l|}{ Secondary school } \\
\hline $1^{\text {st }}$ year & 175 & 185 & 305 & 320 \\
\hline $2^{\text {nd }}$ year & 185 & 205 & 320 & 355 \\
\hline $3^{\text {rd }}$ year & 195 & 225 & 335 & 390 \\
\hline \multicolumn{5}{|l|}{ High school } \\
\hline $1^{\text {st }}$ year & & & 510 & 585 \\
\hline $2^{\text {nd }}$ year & & & 545 & 625 \\
\hline $3^{\text {rd }}$ year & & & 580 & 660 \\
\hline Max HH amount without high-schooler & \multicolumn{2}{|c|}{550} & \multicolumn{2}{|c|}{950} \\
\hline Max HH amount with high-schooler & & & \multicolumn{2}{|c|}{1635} \\
\hline
\end{tabular}

Note: Amounts in nominal pesos. The peso-to-dollar exchange rate was exchange rate was roughly 8 in 1997 and 11 in 2003. Source: www.prospera.gob.mx. 
Table A2: Accounting for Municipality Variation in Early Program Intensity

All municipalities

$R^{2}$ from regression of 1999 enrollment ratio on:

2005 enrollment ratio (r)

Municipality marginality \%-ile dummies (d)

Locality marginality \%-ile shares (s)

(r) and (d)

(r) and (s)

(r), (d), and (s)
(1)

0.84

0.65

0.74

0.38

0.79

0.49

0.86

0.67

0.89

0.73

0.89

0.75

Number of municipalities

2382

1143

Note: Sample municipalities were classified as high or very high marginality in 1990. 
Table A3: Program Impacts on Household and Family Structure

\begin{tabular}{|c|c|c|c|c|c|c|c|c|}
\hline & \multicolumn{4}{|c|}{ Men } & \multicolumn{4}{|c|}{ Women } \\
\hline & \multicolumn{3}{|c|}{2010} & \multirow{2}{*}{$\frac{1990}{(4)}$} & \multicolumn{3}{|c|}{2010} & \multirow{2}{*}{$\begin{array}{c}1990 \\
(8)\end{array}$} \\
\hline & $(1)$ & $(2)$ & $(3)$ & & (5) & $(6)$ & $(7)$ & \\
\hline \multicolumn{9}{|l|}{ A. \# household members } \\
\hline $\begin{array}{l}\text { Enrollment ratio, } 1999 \\
\times \text { post cohort }\end{array}$ & $\begin{array}{c}0.046 \\
{[0.258]}\end{array}$ & $\begin{array}{l}-0.053 \\
{[0.230]}\end{array}$ & $\begin{array}{c}-0.042 \\
{[0.217]}\end{array}$ & $\begin{array}{c}0.314 \\
{[0.297]}\end{array}$ & $\begin{array}{l}-0.240 \\
{[0.209]}\end{array}$ & $\begin{array}{c}-0.082 \\
{[0.190]}\end{array}$ & $\begin{array}{c}0.072 \\
{[0.182]}\end{array}$ & $\begin{array}{c}0.570 \\
{[0.269]^{* *}}\end{array}$ \\
\hline$N$ & 301,140 & 301,140 & 301,140 & 84,489 & 358,339 & 358,339 & 358,339 & 90,433 \\
\hline \multicolumn{9}{|l|}{ B. Living with parent } \\
\hline $\begin{array}{l}\text { Enrollment ratio, } 1999 \\
\times \text { post cohort }\end{array}$ & $\begin{array}{c}-0.110 \\
{[0.042]^{* * *}}\end{array}$ & $\begin{array}{c}-0.128 \\
{[0.038]^{* * *}}\end{array}$ & $\begin{array}{c}-0.114 \\
{[0.038]^{* * *}}\end{array}$ & $\begin{array}{c}0.027 \\
{[0.043]}\end{array}$ & $\begin{array}{c}0.000 \\
{[0.035]}\end{array}$ & $\begin{array}{c}0.011 \\
{[0.032]}\end{array}$ & $\begin{array}{c}0.042 \\
{[0.028]}\end{array}$ & $\begin{array}{c}0.005 \\
{[0.036]}\end{array}$ \\
\hline$N$ & 301,140 & 301,140 & 301,140 & 84,489 & 358,339 & 358,339 & 358,339 & 90,433 \\
\hline \multicolumn{9}{|l|}{ C. Married } \\
\hline $\begin{array}{l}\text { Enrollment ratio, } 1999 \\
\times \text { post cohort }\end{array}$ & $\begin{array}{c}-0.022 \\
{[0.042]}\end{array}$ & $\begin{array}{l}-0.017 \\
{[0.035]}\end{array}$ & $\begin{array}{l}-0.008 \\
{[0.039]}\end{array}$ & $\begin{array}{l}-0.013 \\
{[0.042]}\end{array}$ & $\begin{array}{l}-0.045 \\
{[0.032]}\end{array}$ & $\begin{array}{l}-0.046 \\
{[0.031]}\end{array}$ & $\begin{array}{l}-0.037 \\
{[0.031]}\end{array}$ & $\begin{array}{c}0.013 \\
{[0.036]}\end{array}$ \\
\hline$N$ & 300,735 & 300,735 & 300,735 & 83,698 & 357,825 & 357,825 & 357,825 & 89,719 \\
\hline \multicolumn{9}{|c|}{ D. \# coresident kids born before age 22} \\
\hline $\begin{array}{l}\text { Enrollment ratio, } 1999 \\
\times \text { post cohort }\end{array}$ & - & - & - & - & $\begin{array}{l}-0.104 \\
{[0.079]}\end{array}$ & $\begin{array}{l}-0.065 \\
{[0.075]}\end{array}$ & $\begin{array}{l}-0.071 \\
{[0.080]}\end{array}$ & $\begin{array}{c}0.201 \\
{[0.130]}\end{array}$ \\
\hline$N$ & & & & & 358,339 & 358,339 & 358,339 & 90,433 \\
\hline $\begin{array}{l}\text { Municipality FE, cohort FE } \\
\text { Cohort dummies } \times\end{array}$ & $X$ & $X$ & $X$ & $X$ & $X$ & $X$ & $X$ & $X$ \\
\hline $\begin{array}{l}\text { Muni. marg. \%-ile dummies } \\
\text { Locality marg. \%-ile shares }\end{array}$ & & $X$ & $\begin{array}{l}X \\
X\end{array}$ & & & $X$ & $\begin{array}{l}X \\
X\end{array}$ & \\
\hline
\end{tabular}

Note: Brackets contain standard errors clustered at the municipality level. All regressions additionally control for the interaction of the post indicator with the cumulative enrollment ratio in 2005. Samples include individuals from high and very high marginality municipalities who were aged 9-13 and 16-20 thirteen years before the census. ${ }^{*} p<0.1,{ }^{* *} p<0.05,{ }^{* * *} p<0.01$. 
Table A4: Program Impacts on Spousal Characteristics, Conditional on Marriage

\begin{tabular}{|c|c|c|c|c|c|c|c|c|}
\hline & \multicolumn{4}{|c|}{ Men } & \multicolumn{4}{|c|}{ Women } \\
\hline & \multicolumn{3}{|c|}{2010} & \multirow{2}{*}{$\begin{array}{c}1990 \\
(4)\end{array}$} & \multicolumn{3}{|c|}{2010} & \multirow{2}{*}{$\begin{array}{c}1990 \\
(8)\end{array}$} \\
\hline & $(1)$ & $(2)$ & (3) & & $(5)$ & $(6)$ & (7) & \\
\hline \multicolumn{9}{|l|}{ A. Spouse's education } \\
\hline \multirow{2}{*}{$\begin{array}{l}\text { Enrollment ratio, } 1999 \\
\times \text { post cohort }\end{array}$} & 0.744 & 0.883 & 0.782 & 1.208 & 0.748 & 0.458 & 0.368 & 0.607 \\
\hline & {$[0.475]$} & {$[0.315]^{* * *}$} & {$[0.298]^{* * *}$} & {$[0.637]^{*}$} & {$[0.414]^{*}$} & [0.325] & {$[0.318]$} & {$[0.712]$} \\
\hline$N$ & 195,112 & 195,112 & 195,112 & 55,942 & 229,128 & 229,128 & 229,128 & 63,669 \\
\hline \multicolumn{9}{|l|}{ B. Spouse's age } \\
\hline $\begin{array}{l}\text { Enrollment ratio, } 1999 \\
\times \text { post cohort }\end{array}$ & $\begin{array}{c}0.599 \\
{[0.457]}\end{array}$ & $\begin{array}{c}0.495 \\
{[0.413]}\end{array}$ & $\begin{array}{c}0.064 \\
{[0.429]}\end{array}$ & $\begin{array}{l}-1.087 \\
{[0.719]}\end{array}$ & $\begin{array}{l}-0.561 \\
{[0.469]}\end{array}$ & $\begin{array}{l}-0.629 \\
{[0.467]}\end{array}$ & $\begin{array}{l}-0.489 \\
{[0.485]}\end{array}$ & $\begin{array}{c}0.862 \\
{[0.749]}\end{array}$ \\
\hline$N$ & 195,968 & 195,968 & 195,968 & 55,882 & 230,168 & 230,168 & 230,168 & 63,607 \\
\hline \multicolumn{9}{|l|}{ C. Spouse works } \\
\hline $\begin{array}{l}\text { Enrollment ratio, } 1999 \\
\times \text { post cohort }\end{array}$ & $\begin{array}{c}0.083 \\
{[0.033]^{* *}}\end{array}$ & $\begin{array}{c}0.075 \\
{[0.035]^{* *}}\end{array}$ & $\begin{array}{c}0.067 \\
{[0.037]^{*}}\end{array}$ & $\begin{array}{l}-0.009 \\
{[0.025]}\end{array}$ & $\begin{array}{l}-0.013 \\
{[0.024]}\end{array}$ & $\begin{array}{c}-0.029 \\
{[0.024]}\end{array}$ & $\begin{array}{c}-0.032 \\
{[0.025]}\end{array}$ & $\begin{array}{c}0.032 \\
{[0.034]}\end{array}$ \\
\hline$N$ & 195,450 & 195,450 & 195,450 & 55,511 & 229,390 & 229,390 & 229,390 & 63,420 \\
\hline \multicolumn{9}{|l|}{ D. Spouse's monthly earnings } \\
\hline $\begin{array}{l}\text { Enrollment ratio, } 1999 \\
\times \text { post cohort }\end{array}$ & $\begin{array}{c}150 \\
{[173]}\end{array}$ & $\begin{array}{c}184 \\
{[147]}\end{array}$ & $\begin{array}{c}-15 \\
{[149]}\end{array}$ & $\begin{array}{c}783 \\
{[528]}\end{array}$ & $\begin{array}{c}778 \\
{[250]^{* * *}}\end{array}$ & $\begin{array}{c}732 \\
{[249]^{* * *}}\end{array}$ & $\begin{array}{c}599 \\
{[238]^{* *}}\end{array}$ & $\begin{array}{c}249 \\
{[2,526]}\end{array}$ \\
\hline$N$ & 194,753 & 194,753 & 194,753 & 55,569 & 220,161 & 220,161 & 220,161 & 61,369 \\
\hline $\begin{array}{l}\text { Municipality FE, cohort FE } \\
\text { Cohort dummies } \times\end{array}$ & $X$ & $X$ & $X$ & $X$ & $X$ & $x$ & $X$ & $X$ \\
\hline $\begin{array}{l}\text { Muni. marg. \%-ile dummies } \\
\text { Locality marg. \%-ile shares }\end{array}$ & & $X$ & $\begin{array}{l}X \\
X\end{array}$ & & & $x$ & $\begin{array}{l}X \\
X\end{array}$ & \\
\hline
\end{tabular}

Note: Brackets contain standard errors clustered at the municipality level. All regressions additionally control for the interaction of the post indicator with the cumulative enrollment ratio in 2005. Samples include married individuals from high and very high marginality municipalities who were aged 9-13 and 16-20 thirteen years before the census. ${ }^{*} p<0.1,{ }^{* *} p<0.05,{ }^{* * *} p<0.01$. 
Table A5: Robustness Check for Key Outcomes: Assigning Exposure for Out-of-State Migrants

\begin{tabular}{|c|c|c|c|c|}
\hline & \multicolumn{2}{|c|}{ Men } & \multicolumn{2}{|c|}{ Women } \\
\hline & $\begin{array}{l}\text { Municipality } \\
5 \text { years earlier } \\
\text { (1) }\end{array}$ & $\begin{array}{l}\text { State of } \\
\text { birth } \\
(2)\end{array}$ & $\begin{array}{l}\text { Municipality } \\
5 \text { years earlier } \\
\text { (3) }\end{array}$ & $\begin{array}{c}\text { State of } \\
\text { birth } \\
(4)\end{array}$ \\
\hline A. Years of education & $\begin{array}{c}1.138 \\
{[0.372]^{* * *}}\end{array}$ & $\begin{array}{c}1.524 \\
{[0.332]^{* * *}}\end{array}$ & $\begin{array}{c}1.626 \\
{[0.378]^{* * *}}\end{array}$ & $\begin{array}{c}1.906 \\
{[0.379]^{* * *}}\end{array}$ \\
\hline$N$ & 299,237 & 303,151 & 355,986 & 358,237 \\
\hline B. At least some middle school & $\begin{array}{c}0.169 \\
{[0.051]^{* * *}}\end{array}$ & $\begin{array}{c}0.218 \\
{[0.037]^{* * *}}\end{array}$ & $\begin{array}{c}0.298 \\
{[0.039]^{* * *}}\end{array}$ & $\begin{array}{c}0.336 \\
{[0.046]^{* * *}}\end{array}$ \\
\hline$N$ & 299,906 & 303,831 & 356,801 & 359,062 \\
\hline C. Working & $\begin{array}{l}-0.011 \\
{[0.036]}\end{array}$ & $\begin{array}{l}-0.007 \\
{[0.038]}\end{array}$ & $\begin{array}{c}0.060 \\
{[0.046]}\end{array}$ & $\begin{array}{c}0.095 \\
{[0.052]^{*}}\end{array}$ \\
\hline$N$ & 299,515 & 303,411 & 357,018 & 359,234 \\
\hline D. Working for wage & $\begin{array}{c}0.061 \\
{[0.042]}\end{array}$ & $\begin{array}{c}0.070 \\
{[0.041]^{*}}\end{array}$ & $\begin{array}{c}0.066 \\
{[0.039]}\end{array}$ & $\begin{array}{c}0.086 \\
{[0.039]^{* *}}\end{array}$ \\
\hline$N$ & 293,165 & 297,017 & 354,440 & 356,612 \\
\hline E. Monthly labor earnings & $\begin{array}{c}735 \\
{[455]}\end{array}$ & $\begin{array}{c}984 \\
{[354]^{* *}}\end{array}$ & $\begin{array}{c}225 \\
{[182]}\end{array}$ & $\begin{array}{c}432 \\
{[198]^{* *}}\end{array}$ \\
\hline$N$ & 288,431 & 291,988 & 354,156 & 356,187 \\
\hline F. Housing index & $\begin{array}{c}0.265 \\
{[0.147]^{*}} \\
294,969\end{array}$ & $\begin{array}{c}0.260 \\
{[0.147]^{*}} \\
298,754\end{array}$ & $\begin{array}{c}0.267 \\
{[0.131]^{*}} \\
351,077\end{array}$ & $\begin{array}{c}0.293 \\
{[0.135]^{* *}} \\
353,219\end{array}$ \\
\hline G. Durable goods index & $\begin{array}{c}0.152 \\
{[0.072]^{* *}}\end{array}$ & $\begin{array}{c}0.200 \\
{[0.083]^{* *}}\end{array}$ & $\begin{array}{c}0.264 \\
{[0.107]^{* *}}\end{array}$ & $\begin{array}{c}0.335 \\
{[0.133]^{* *}}\end{array}$ \\
\hline$N$ & 295,927 & 299,722 & 352,337 & 354,492 \\
\hline H. Cross-municipal migration & $\begin{array}{c}0.085 \\
{[0.074]}\end{array}$ & $\begin{array}{c}0.128 \\
{[0.068]^{*}}\end{array}$ & $\begin{array}{c}0.082 \\
{[0.063]}\end{array}$ & $\begin{array}{c}0.079 \\
{[0.067]}\end{array}$ \\
\hline$N$ & 301,140 & 305,036 & 358,339 & 360,565 \\
\hline I. Urban residence & $\begin{array}{c}0.082 \\
{[0.076]}\end{array}$ & $\begin{array}{c}0.115 \\
{[0.070]}\end{array}$ & $\begin{array}{c}0.090 \\
{[0.069]}\end{array}$ & $\begin{array}{c}0.113 \\
{[0.073]}\end{array}$ \\
\hline$N$ & 301,140 & 305,039 & 358,339 & 360,565 \\
\hline
\end{tabular}

Note: Coefficients on the post indicator interacted with the cumulative enrollment ratio in 1999, with standard errors clustered at the state level in brackets. All regressions control for the post indicator interacted with the cumulative enrollment ratio in 2005, cohort indicators, and the main effects of the 1999 and 2005 enrollment ratios. The main effects of these variables are included instead of municipality fixed effects because no municipality is assigned to out-of-state migrants in columns (2) and (4). Columns (1) and (3) apply this regression specification to the original 2010 sample, assigning program exposure based on municipality of residence in 2005. Columns (2) and (4) add to the sample out-of-state migrants whose birth state average marginality index exceeds the municipal threshold for high or very high marginality, assigning program exposure based on state of birth. An out-of-state migrant is defined as an individual whose birth state differs from her state of residence in 2005. 
Table A6: Robustness Check for Key Outcomes: Men

\begin{tabular}{|c|c|c|c|c|c|c|c|}
\hline & \multicolumn{3}{|c|}{ Main results } & \multicolumn{4}{|c|}{ Robustness checks } \\
\hline & (1) & $(2)$ & (3) & (4) & $(5)$ & $(6)$ & (7) \\
\hline \multirow[t]{2}{*}{ A. Years of education } & 1.026 & 0.866 & 0.596 & 0.696 & 0.621 & 0.597 & 0.500 \\
\hline & {$[0.360]^{* * *}$} & {$[0.327]^{* * *}$} & {$[0.315]^{*}$} & {$[0.322]^{* *}$} & {$[0.321]^{*}$} & {$[0.315]^{*}$} & {$[0.314]$} \\
\hline$N$ & 299,237 & 299,237 & 299,237 & 299,237 & 299,212 & 299,237 & 299,237 \\
\hline \multirow[t]{2}{*}{ B. At least some middle school } & 0.156 & 0.163 & 0.130 & 0.138 & 0.141 & 0.137 & 0.108 \\
\hline & {$[0.050]^{* * *}$} & {$[0.043]^{* * *}$} & {$[0.043]^{* * *}$} & {$[0.045]^{* * *}$} & {$[0.043]^{* * *}$} & {$[0.043]^{* * *}$} & {$[0.040]^{* * *}$} \\
\hline$N$ & 299,906 & 299,906 & 299,906 & 299,906 & 299,881 & 299,906 & 299,906 \\
\hline \multirow[t]{2}{*}{ C. Working } & -0.015 & -0.008 & 0.001 & 0.021 & -0.007 & 0.002 & -0.009 \\
\hline & {$[0.030]$} & {$[0.028]$} & {$[0.030]$} & {$[0.030]$} & {$[0.031]$} & {$[0.031]$} & {$[0.030]$} \\
\hline$N$ & 299,515 & 299,515 & 299,515 & 299,515 & 299,490 & 299,515 & 299,515 \\
\hline \multirow[t]{2}{*}{ D. Working for wage } & 0.032 & 0.072 & 0.059 & 0.059 & 0.056 & 0.059 & 0.044 \\
\hline & {$[0.040]$} & {$[0.039]^{*}$} & {$[0.042]$} & {$[0.042]$} & {$[0.042]$} & {$[0.041]$} & {$[0.041]$} \\
\hline$N$ & 293,165 & 293,165 & 293,165 & 293,165 & 293,140 & 293,165 & 293,165 \\
\hline \multirow[t]{2}{*}{ E. Monthly labor earnings } & 494 & 729 & 268 & 250 & 225 & 258 & 194 \\
\hline & [383] & {$[256]^{* * *}$} & [261] & {$[255]$} & [258] & [260] & [269] \\
\hline$N$ & 288,431 & 288,431 & 288,431 & 288,431 & 288,406 & 288,431 & 288,431 \\
\hline \multirow[t]{2}{*}{ F. Housing index } & 0.209 & 0.239 & 0.199 & 0.151 & 0.212 & 0.194 & 0.142 \\
\hline & {$[0.114]^{*}$} & {$[0.099]^{* *}$} & {$[0.103]^{*}$} & [0.097] & {$[0.108]^{* *}$} & {$[0.101]^{*}$} & {$[0.085]^{*}$} \\
\hline$N$ & 294,969 & 294,969 & 294,969 & 294,969 & 294,944 & 294,969 & 294,969 \\
\hline \multirow[t]{2}{*}{ G. Durable goods index } & 0.105 & 0.098 & 0.050 & 0.005 & 0.065 & 0.045 & 0.003 \\
\hline & {$[0.110]$} & {$[0.094]$} & [0.097] & {$[0.096]$} & {$[0.101]$} & {$[0.094]$} & {$[0.081]$} \\
\hline$N$ & 295,927 & 295,927 & 295,927 & 295,927 & 295,903 & 295,927 & 295,927 \\
\hline \multirow[t]{2}{*}{ H. Cross-municipal migration } & 0.067 & 0.104 & 0.072 & 0.063 & 0.078 & 0.069 & 0.069 \\
\hline & {$[0.052]$} & {$[0.039]^{* * *}$} & {$[0.041]^{*}$} & {$[0.039]$} & {$[0.041]^{*}$} & {$[0.040]^{*}$} & {$[0.040]^{*}$} \\
\hline$N$ & 301,140 & 301,140 & 301,140 & 301,140 & 301,115 & 301,140 & 301,140 \\
\hline \multirow[t]{2}{*}{ I. Urban residence } & 0.066 & 0.081 & 0.077 & 0.067 & 0.082 & 0.074 & 0.061 \\
\hline & {$[0.050]$} & {$[0.043]^{*}$} & {$[0.043]^{*}$} & {$[0.042]$} & {$[0.044]^{*}$} & {$[0.042]^{*}$} & {$[0.040]$} \\
\hline$N$ & 301,140 & 301,140 & 301,140 & 301,140 & 301,115 & 301,140 & 301,140 \\
\hline Municipality FE, cohort FE & $X$ & $X$ & $x$ & $X$ & $X$ & $x$ & $X$ \\
\hline \multicolumn{8}{|l|}{ Cohort dummies $\times$} \\
\hline Muni. marg. \%-ile dummies & & $X$ & $x$ & $X$ & $X$ & $x$ & $X$ \\
\hline Locality marg. \%-ile shares & & & $x$ & $X$ & $X$ & $x$ & $X$ \\
\hline Muni. marg. components & & & & $X$ & & & \\
\hline 1994 PRI vote share & & & & & $x$ & & \\
\hline$\Delta$ schools p.c., $1995-00 \&$ 2000-05 & & & & & & $x$ & \\
\hline$\Delta$ homicide rate, $2006-10$ & & & & & & & $\mathrm{X}$ \\
\hline
\end{tabular}

Note: Coefficients on the post indicator interacted with the cumulative enrollment ratio in 1999, with standard errors clustered at the state level in brackets. Marginality components include the share living in communities with less than 5000 inhabitants, the share earning less than twice the minimum wage, the share illiterate, and the shares with less than primary school, without a toilet, without electricity, without running water, with crowding, and with a dirt floor, all in 1990. All regressions additionally control for the interaction of the post indicator with the cumulative enrollment ratio in 2005. Sample includes individuals in the 2010 Census from high and very high marginality municipalities who were aged 9-13 and 16-20 in 1997. ${ }^{*} p<0.1,{ }^{* *} p<0.05,{ }^{* * *} p<0.01$. 
Table A7: Robustness Check for Key Outcomes: Women

\begin{tabular}{|c|c|c|c|c|c|c|c|}
\hline & \multicolumn{3}{|c|}{ Main results } & \multicolumn{4}{|c|}{ Robustness checks } \\
\hline & $(1)$ & $(2)$ & (3) & $(4)$ & (5) & (6) & (7) \\
\hline \multirow[t]{2}{*}{ A. Years of education } & 1.570 & 1.374 & 1.032 & 1.207 & 1.073 & 1.041 & 0.818 \\
\hline & {$[0.307]^{* * *}$} & {$[0.311]^{* * *}$} & {$[0.309]^{* * *}$} & {$[0.316]^{* * *}$} & {$[0.316]^{* * *}$} & {$[0.311]^{* * *}$} & {$[0.304]^{* * *}$} \\
\hline$N$ & 355,986 & 355,986 & 355,986 & 355,986 & 355,933 & 355,986 & 355,986 \\
\hline \multirow[t]{2}{*}{ B. At least some middle school } & 0.293 & 0.302 & 0.225 & 0.229 & 0.226 & 0.231 & 0.207 \\
\hline & {$[0.038]^{* * *}$} & {$[0.039]^{* * *}$} & {$[0.039]^{* * *}$} & {$[0.041]^{* * *}$} & {$[0.039]^{* * *}$} & {$[0.039]^{* * *}$} & {$[0.040]^{* * *}$} \\
\hline$N$ & 356,801 & 356,801 & 356,801 & 356,801 & 356,748 & 356,801 & 356,801 \\
\hline \multirow[t]{2}{*}{ C. Working } & 0.053 & 0.062 & 0.093 & 0.107 & 0.078 & 0.091 & 0.098 \\
\hline & {$[0.032]^{*}$} & {$[0.031]^{* *}$} & {$[0.031]^{* * *}$} & {$[0.033]^{* * *}$} & {$[0.032]^{* *}$} & {$[0.031]^{* * *}$} & {$[0.032]^{* * *}$} \\
\hline$N$ & 357,018 & 357,018 & 357,018 & 357,018 & 356,965 & 357,018 & 357,018 \\
\hline \multirow{2}{*}{ D. Working for wage } & 0.063 & 0.077 & 0.073 & 0.078 & 0.063 & 0.072 & 0.069 \\
\hline & {$[0.029]^{* *}$} & {$[0.027]^{* * *}$} & {$[0.027]^{* * *}$} & {$[0.029]^{* * *}$} & {$[0.028]^{* *}$} & {$[0.027]^{* * *}$} & {$[0.028]^{* *}$} \\
\hline$N$ & 354,440 & 354,440 & 354,440 & 354,440 & 354,387 & 354,440 & 354,440 \\
\hline \multirow[t]{2}{*}{ E. Monthly labor earnings } & 236 & 268 & 255 & 303 & 212 & 252 & 252 \\
\hline & {$[137]^{*}$} & {$[135]^{* *}$} & {$[139]^{*}$} & {$[142]^{* *}$} & [139] & {$[139]^{*}$} & {$[141]^{*}$} \\
\hline$N$ & 352,835 & 352,835 & 354,156 & 354,156 & 354,103 & 354,156 & 354,156 \\
\hline \multirow[t]{2}{*}{ F. Housing index } & 0.243 & 0.253 & 0.187 & 0.177 & 0.182 & 0.185 & 0.158 \\
\hline & {$[0.065]^{* * *}$} & {$[0.070]^{* * *}$} & {$[0.072]^{* * *}$} & {$[0.069]^{* *}$} & {$[0.071]^{* *}$} & {$[0.072]^{* *}$} & {$[0.074]^{* *}$} \\
\hline$N$ & 351,077 & 351,077 & 351,077 & 351,077 & 351,024 & 351,077 & 351,077 \\
\hline \multirow{2}{*}{ G. Durable goods index } & 0.229 & 0.194 & 0.146 & 0.130 & 0.146 & 0.148 & 0.115 \\
\hline & {$[0.073]^{* * *}$} & {$[0.062]^{* * *}$} & {$[0.062]^{* *}$} & {$[0.063]^{* *}$} & {$[0.062]^{* *}$} & {$[0.062]^{* *}$} & {$[0.063]^{*}$} \\
\hline$N$ & 352,337 & 352,337 & 352,337 & 352,337 & 352,284 & 352,337 & 352,337 \\
\hline \multirow[t]{2}{*}{ H. Cross-municipal migration } & 0.073 & 0.076 & 0.062 & 0.051 & 0.059 & 0.061 & 0.056 \\
\hline & {$[0.031]^{* *}$} & {$[0.029]^{* * *}$} & {$[0.029]^{* *}$} & {$[0.028]^{*}$} & {$[0.029]^{* *}$} & {$[0.029]^{* *}$} & {$[0.030]^{*}$} \\
\hline$N$ & 358,339 & 358,339 & 358,339 & 358,339 & 358,286 & 358,339 & 358,339 \\
\hline \multirow[t]{2}{*}{ I. Urban residence } & 0.110 & 0.086 & 0.044 & 0.031 & 0.043 & 0.044 & 0.035 \\
\hline & {$[0.034]^{* * *}$} & {$[0.032]^{* * *}$} & {$[0.033]$} & {$[0.031]$} & {$[0.033]$} & [0.033] & {$[0.034]$} \\
\hline$N$ & 358,339 & 358,339 & 358,339 & 358,339 & 358,286 & 358,339 & 358,339 \\
\hline Municipality FE, cohort FE & $x$ & $x$ & $x$ & $x$ & $x$ & $X$ & $X$ \\
\hline \multicolumn{8}{|l|}{ Cohort dummies $\times$} \\
\hline Muni. marg. \%-ile dummies & & $x$ & $x$ & $x$ & $x$ & $x$ & $x$ \\
\hline Locality marg. \%-ile shares & & & $x$ & $x$ & $x$ & $x$ & $x$ \\
\hline Muni. marg. components & & & & $x$ & & & \\
\hline 1994 PRI vote share & & & & & $x$ & & \\
\hline$\Delta$ schools p.c., $1995-00 \& 2000-05$ & & & & & & $X$ & \\
\hline$\Delta$ homicide rate, $2006-10$ & & & & & & & $X$ \\
\hline
\end{tabular}

Note: Coefficients on the post indicator interacted with the cumulative enrollment ratio in 1999, with standard errors clustered at the state level in brackets. Marginality components include the share living in communities with less than 5000 inhabitants, the share earning less than twice the minimum wage, the share illiterate, and the shares with less than primary school, without a toilet, without electricity, without running water, with crowding, and with a dirt floor, all in 1990. All regressions additionally control for the interaction of the post indicator with the cumulative enrollment ratio in 2005. Sample includes individuals in the 2010 Census from high and very high marginality municipalities who were aged 9-13 and 16-20 in 1997. ${ }^{*} p<0.1,{ }^{* *} p<0.05,{ }^{* * *} p<0.01$. 